\title{
Avaliação da proteína A do surfactante na síndrome hepatopulmonar em ratos
}

Dissertação apresentada à Faculdade de Medicina da Universidade de São Paulo para obtenção do título de Mestre em Ciências

Programa de Ciências em Gastroenterologia

Orientador: Dr. Wellington Andraus

São Paulo

2013 
Dados Internacionais de Catalogação na Publicação (CIP)

Preparada pela Biblioteca da

Faculdade de Medicina da Universidade de São Paulo

Creprodução autorizada pelo autor

Nacif, Lucas Souto

Avaliação da proteína A do surfactante na síndrome hepatopulmonar em ratos / Lucas Souto Nacif. -- São Paulo, 2013.

Dissertação(mestrado)--Faculdade de Medicina da Universidade de São Paulo.

Programa de Ciências em Gastroenterologia.

Orientador: Wellington Andraus.

Descritores: 1.Síndrome hepatopulmonar 2.Proteína A associada a surfactante pulmonar 3.Cirrose hepática experimental 4.Ratos

USP/FM/DBD-029/13 


\section{Dedicatória}

Dedico este trabalho primeiramente aos meus queridos avós que foram e são exemplos de pessoas e de vida.

E especialmente aos meus pais, por serem quem são e por estarem presentes em nossas vidas (meus irmãos) em todos os momentos. Sempre fazendo o possível e o impossível para proporcionarem um ambiente confortável, equilibrado e de conquistas, sempre ensinando respeito ao próximo e o aprendizado com as derrotas.

Aos meus queridos irmãos por sempre estarem ao meu lado, e cada um de sua maneira fazendo-se imprescindível em meus passos.

A minha namorada / noiva que com tão pouco tempo se tornou uma pessoa importante em minha vida.

Aos meus amigos que por muitas vezes não pude estar presente como gostaria. 


\section{Agradecimentos}

Ao Prof. Dr. Luiz Augusto Carneiro D’Albuquerque primeiramente pela oportunidade para a realização deste trabalho, pela confiança concedida, pelos inúmeros exemplos de conquistas, ensinamentos e de formação profissional.

Ao Dr. Wellington Andraus pela intocável orientação neste trabalho. Sinto me honrado por ter sido seu primeiro orientando de pós graduação e pelo aprendizado com inúmeros ensinamentos, correções e aconselhamentos.

À Dra. Flávia Saldanha Kubrusly pela busca incansável pelos resultados e realização deste trabalho.

À Nilza Aparecida Trindade Molan pela amizade adquirida, constante dedicação e profissionalismo.

À Márcia Saldanha Kubrusly pela amizade conquistada, pelas inúmeras ajudas fornecidas durante a elaboração deste trabalho, desde os passos iniciais, realização e correção dos dados estatísticos, assim como a sua finalização.

Aos amigos do Laboratório de Investigação Médica da Disciplina de Transplantes de Órgãos do Aparelho Digestivo (LIM-37) nada seria possível sem essa colaboração.

Aos amigos e colegas da Disciplina de Transplantes de Órgãos do Aparelho Digestivo e ao Serviço de Transplante de Órgãos do Aparelho Digestivo do Hospital 
das Clínicas da Faculdade de Medicina da USP que me proporcionaram grande desenvolvimento pessoal e profissional durante a elaboração deste trabalho.

Aos colegas do Instituto Butantan devido a incansável busca pelo resultado e as inúmeras vezes sempre disponíveis e colaborativos.

À senhora Vilma de Jesus Libério pela disponibilidade e atenção que foram fundamentais para a elaboração deste trabalho. 
"A persistência é o menor caminho do êxito".

Charles Chaplin 


\section{Normalização Adotada}

Esta dissertação está de acordo com as seguintes normas, em vigor no momento desta publicação:

Referências: adaptado de International Committee of Medical Journals Editors (Vancouver).

Universidade de São Paulo. Faculdade de Medicina. Divisão de Biblioteca e Documentação. Guia de apresentação de dissertações, teses e monografias. Elaborado por Anneliese Carneiro da Cunha, Maria Julia de A. L. Freddi, Maria F. Crestana, Marinalva de Souza Aragão, Suely Campos Cardoso, Valéria Vilhena. 3a ed. São Paulo: Divisão de Biblioteca e Documentação; 2011.

Abreviaturas dos títulos dos periódicos de acordo com List of Journals Indexed in Index Medicus. 


\section{SUMÁRIO}

LISTA DE ABREVIATURAS E SIGLAS

LISTA DE TABELAS

LISTA DE GRÁFICOS

LISTA DE FIGURAS

RESUMO

SUMMARY

1 INTRODUÇÃO

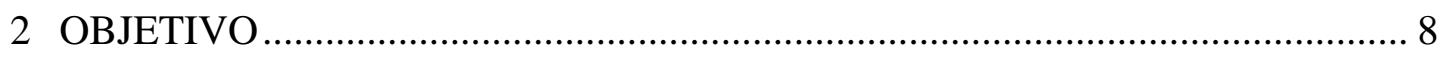

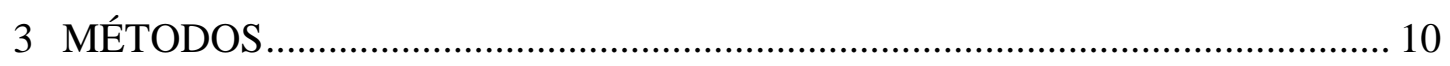

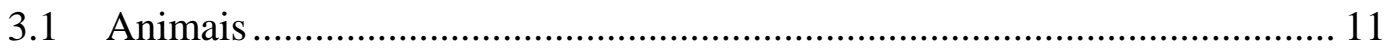

3.2 Desenho do estudo/ modelo experimental ............................................ 12

3.3 Análise de sangue arterial e venoso ....................................................... 14

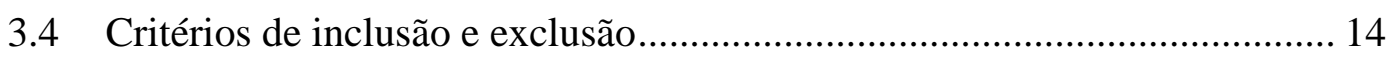

3.5 Avaliação da proteína A do surfactante (SP-A) ....................................... 15

3.5.1 Curva de calibração do soro policlonal de coelho anti-SP-A suína

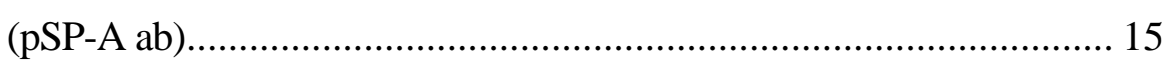

3.6 Atividade da mieloperoxidase .............................................................. 17

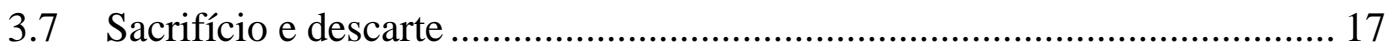

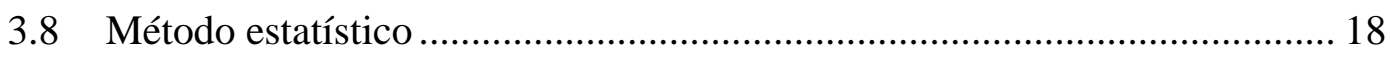

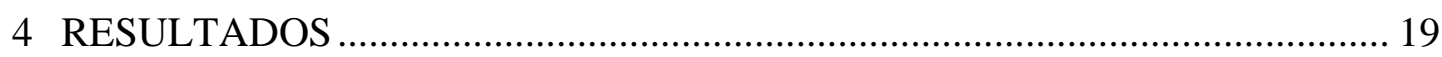

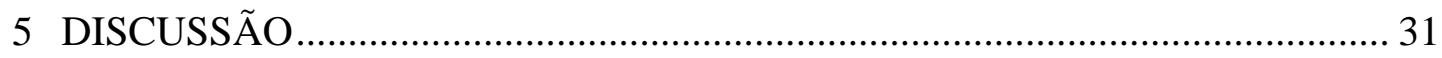

6 CONCLUSÃO

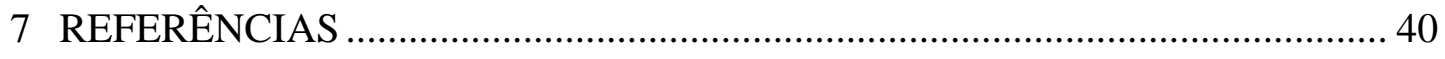

APÊNDICES 


\section{LISTA DE ABREVIATURAS E SIGLAS}

\begin{tabular}{|c|c|}
\hline AST & aspartato aminotransferase \\
\hline ALT & alanino aminotransferase \\
\hline BT & bilirrubina total \\
\hline $\mathrm{BD}$ & bilirrubina direta \\
\hline LVBP & ligadura da via biliar principal \\
\hline DO & densidade óptica \\
\hline $\mathrm{DP}$ & desvio padrão \\
\hline DVIP & dilatações vasculares intrapulmonares \\
\hline ET-1 & endotelina 1 \\
\hline ET A & endotelina $\mathrm{A}$ \\
\hline ET B & endotelina B \\
\hline eONS & óxido nítrico sintase endotelial \\
\hline FA & fosfatase alcalina \\
\hline GGT & gama glutamil transferase \\
\hline iONS & óxido nítrico sintase induzível \\
\hline LIM & laboratório de investigação médicas \\
\hline MPO & mieloperoxidase \\
\hline $\mathrm{ON}$ & óxido nítrico \\
\hline $\mathrm{CO}$ & monóxido de carbono \\
\hline
\end{tabular}



$\mathrm{PaO} 2$ pressão arterial de oxigênio
SHP síndrome hepatopulmonar
Sat $\mathrm{O} 2$ saturação de oxigênio
SP-A proteína A do surfactante
TNF- $\alpha$ fator de necrose tumoral alfa
TGF- $\beta$ fator de transformação do crescimento beta
ELISA ensaio imunoenzimático
EDTA ácido etilenodiaminotretacético 


\section{LISTA DE TABELAS}

Tabela 1 - Padronização da concentração das amostras. Diluição do soro e homogenato, e a quantidade da proteína SP-A presente 16

Tabela 2 - Resultado dos valores da bioquímica laboratorial, análise da gasometria arterial e da atividade da mieloperoxidase pulmonar 22

Tabela 3 - Avaliação da proteína A do surfactante sérica e no homogenato pulmonar 28 


\section{LISTA DE GRÁFICOS}

Gráfico 1 - Relação entre SP-A suína e Densidade óptica...................................... 16

Gráfico 2 - Avaliação da alanino aminotransferase (ALT) entre os grupos controle, Sham e ligadura da via biliar principal (LVBP)...

Gráfico 3 - Avaliação da aspartato aminotransferase (AST) entre os grupos controle, Sham e ligadura da via biliar principal (LVBP).

Gráfico 4 - Avaliação da Bilirrubina Total e Bilirrubina Direta nos grupos controle, Sham e ligadura da via biliar principal (LVBP)

Gráfico 5 - Avaliação da GGT (gama glutamil transferase) nos grupos controle, Sham e ligadura da via biliar principal (LVBP).

Gráfico 6 - Avaliação da fosfatase alcalina nos três grupos controle, Sham e ligadura da via biliar principal (LVBP).

Gráfico 7 - Avaliação da $\mathrm{PaO} 2$ nos grupos controle, Sham e ligadura da via biliar principal (LVBP).

Gráfico 8 - Avaliação saturação de oxigênio nos grupos controle, Sham e ligadura da via biliar principal (LVBP).

Gráfico 9 - Avaliação da mieloperoxidase (MPO) nos grupos controle, Sham e ligadura da via biliar principal(LVBP).

Gráfico 10 - Avaliação da SP-A no homogenato pulmonar nos três grupos.

Gráfico 11 - Avaliação da SP-A sérica nos três grupos controle, Sham e ligadura da via biliar principal 


\section{LISTA DE FIGURAS}

Figura 1 - Fisiopatologia da SHP descrita a partir do modelo experimental

Figura 2 - Fluxograma do experimento

Figura 3 - Aspecto macroscópico do fígado e pulmão no grupo Ligadura da via biliar principal (A) e grupo Sham (B).

Figura 4 - Achados histológicos ilustrativos no Grupo Ligadura da via biliar principal (LBVP) demonstrando aspecto de síndrome hepatopulmonar..... 30 


\section{RESUMO}

Nacif LS. Avaliação da proteína A do surfactante na síndrome hepatopulmonar em ratos [dissertação]. São Paulo: Faculdade de Medicina, Universidade de São Paulo; 2013. 44p.

INTRODUÇÃO: A síndrome hepatopulmonar (SHP) é formada por uma tríade: doença hepática, dilatação vascular intrapulmonar e alteração dos gases no sangue. Sua patogenia não está bem definida, mas especula-se que a combinação de fatores, tais como o desequilíbrio da resposta de receptores da endotelina, a remodelação microvascular pulmonar, a predisposição genética e a translocação de bactérias sejam os desencadeadores das alterações que levarão ao desenvolvimento da síndrome. O pulmão é o local principal de produção do surfactante (células alveolares epiteliais do tipo II) e desempenha um papel importante na lesão e doenças inflamatórias pulmonares. Até o momento não há relatos de avaliação do surfactante na cirrose ou na SHP. OBJETIVO: Avaliar a concentração da proteína A do surfactante na síndrome hepatopulmonar induzida em ratos. MÉTODO: Três grupos de ratos foram divididos em controle, Sham e grupo experimental de SHP. Grupo controle: somente coleta dos exames; grupo Sham: realizada a cirurgia simulada; e o grupo do modelo experimental: indução de cirrose biliar secundária através da ligadura da via biliar principal. Foi realizado a avaliação da proteína A do surfactante no homogenato pulmonar e sérico através do método imunoenzimático ELISA indireto. RESULTADOS: Observou-se depois de 28 dias a evidência de cirrose em todos os ratos operados e a apresentação de SHP em $85 \%$ dos ratos. No homogenato do pulmão no grupo LVBP e Sham, a avaliação da proteína A do surfactante (SP-A) apresentou níveis inferiores quando comparados com o grupo controle ( $\mathrm{p}<0,01$ ). No soro, a SP-A apresentou os mesmos níveis nos grupos LVBP e controle, e mostrou-se reduzida no grupo Sham. CONCLUSÃO: O modelo experimental de SHP mostrou uma redução na proteína A do surfactante no pulmão. Há também um desequilíbrio entre a proteína A do surfactante pulmonar e sérica na síndrome hepatopulmonar.

Descritores: 1.Síndrome hepatopulmonar 2.Proteína A associada a surfactante pulmonar 3.Cirrose hepática experimental 4.Ratos 


\section{SUMMARY}

Nacif LS. Evaluation of surfactant protein A in hepatopulmonary syndrome in rats [dissertation]. São Paulo: "Faculdade de Medicina, Universidade de São Paulo"; 2013. 44p.

INTRODUCTION: Hepatopulmonary syndrome (HPS) is formed by a triad: liver disease, intrapulmonary vascular dilatation and changes in blood gases. Its pathogenesis is not well defined, but it is speculated that the combination of factors such as the imbalance of endothelin receptors response, pulmonary microvascular remodeling, genetic predisposition, and bacterial translocation lead to intrapulmonary vascular dilatation. The lung is the primary site of surfactant production (alveolar epithelial type II cells) and plays an important role in inflammatory lung injury and diseases. To date, there are no reports of surfactant evaluation in cirrhosis, neither in HPS. OBJECTIVE: Evaluation of surfactant protein A in hepatopulmonary syndrome in rats. METHOD: Three groups of rats were divided into control, sham and experimental HPS groups. Control group: only exams were collected; Sham group: was performed the simulate surgery; and the experimental group: was induced secondary biliary cirrhosis. The experimental model used to induce a secondary biliary cirrhosis were the common bile duct ligation. Conducted evaluation of surfactant protein A in lung homogenate and serum by ELISA immunoassay method. RESULTS: It was observed after 28 days the evidence of cirrhosis in all operated rats. The lung homogenate surfactant protein A (SP-A) showed lower levels in HPS and sham groups in comparison with the control group ( $\mathrm{p}<0.01$ ). In serum, the SP-A showed the same levels in HPS and control groups, and it was diminished in the sham group. CONCLUSION: The experimental model of HPS showed a reduction in surfactant protein A in lung. There is also an imbalance between lung and serum surfactant protein A levels in the hepatopulmonary syndrome.

Descriptors: 1.Hepatopulmonary syndrome 2.Protein A associated pulmonar surfactant 3.Experimental cirrhosis 4.Rats 
A primeira publicação descrevendo a associação entre doença do fígado e pulmonar foi em 1884 quando Fluckiger et al. relataram o caso de uma mulher de 37 anos com cirrose, cianose e baqueteamento digital, na época atribuídos à sífilis. Somente em 1977, Kennedy e Knudson sugeriram a descrição do termo síndrome hepatopulmonar. ${ }^{(1-4)}$

A síndrome hepatopulmonar (SHP) é considerada uma entidade clínica composta pela tríade: doença hepática, dilatações vasculares intrapulmonares (DVIP) e hipoxemia arterial. Esta condição está presente em $4 \%$ a $32 \%$ dos pacientes com cirrose. ${ }^{(3,5)}$ A classificação proposta por Krowka e Cortese em 1992, baseada nos níveis de oxigenação arterial e achados angiográficos, propõe: Tipo I - dilatação pré capilar com resposta satisfatória à administração de oxigênio a 100\%; Tipo II vasodilatações pequenas e localizadas, com resposta pobre a administração do oxigênio. ${ }^{(6)}$

A hipoxemia é geralmente progressiva, e a mortalidade apresenta-se aumentada em pacientes cirróticos com SHP. A gravidade da SHP, descrita em 2004 por Rodriguez-Roisin, é proporcional à diminuição da pressão arterial de oxigênio (PaO2): $\mathrm{PaO} 2<50 \mathrm{mmHg}$ é considerada muito grave; $\mathrm{PaO} 2 \geq 50 \mathrm{mmHg}$ e $<60 \mathrm{mmHg}$ é grave; e $\mathrm{PaO} 2 \geq 60$ e $<80 \mathrm{mmHg}$ é considerada moderada. ${ }^{(7)}$

Sua etiopatogenia não está bem definida, mas especula-se que a associação de fatores como o desequilíbrio na resposta dos receptores vasculares de endotelina, o 
remodelamento microvascular pulmonar, a predisposição genética e a translocação bacteriana propiciem as dilatações vasculares intrapulmonares, como podemos observar na figura abaixo (Figura 1). Recentemente tem se dado ênfase ao papel da endotelina (ET-1) presente na microcirculação pulmonar na gênese da DVIP. Em condições normais, a ET-1 produzida pelo fígado tem a função de regulação do tônus vascular pulmonar, levando o receptor endotelina A (ET A) à ocasionar vasoconstricção. Entretanto o receptor localizado no endotélio vascular pulmonar (ET B) produz vasodilatação pela síntese do óxido nítrico $(\mathrm{ON})$ estimulando a óxido nítrico sintase endotelial (eONS). Durante a doença hepática, a chegada da ET-1 produzida pelo fígado interage com o receptor pulmonar (ET B) produzindo vasodilatação. Nos casos de cirrose, os níveis de fator de necrose tumoral alfa (TNF- $\alpha$ ) aumentam e contribuem para o acúmulo de macrófagos no lúmen vascular pulmonar, que estimulam a enzima produtora de ON (iONS) ocasionando vasodilatação pulmonar. ${ }^{(1-5,8-15)}$

As características fisiopatológicas da SHP experimental induzida pela ligadura do ducto biliar comum (ligadura do colédoco) são alterações da microvasculatura pulmonar, incluindo vasodilatação, acúmulo intravascular de monócitos e a angiogênese. Alguns autores mostraram um aumento na expressão da enzima óxido nítrico sintase induzível (iNOS) nos pulmões dos animais com ligadura do colédoco e que pode também contribuir para a produção de ON local durante a progressão da SHP. ${ }^{(3)}$ 


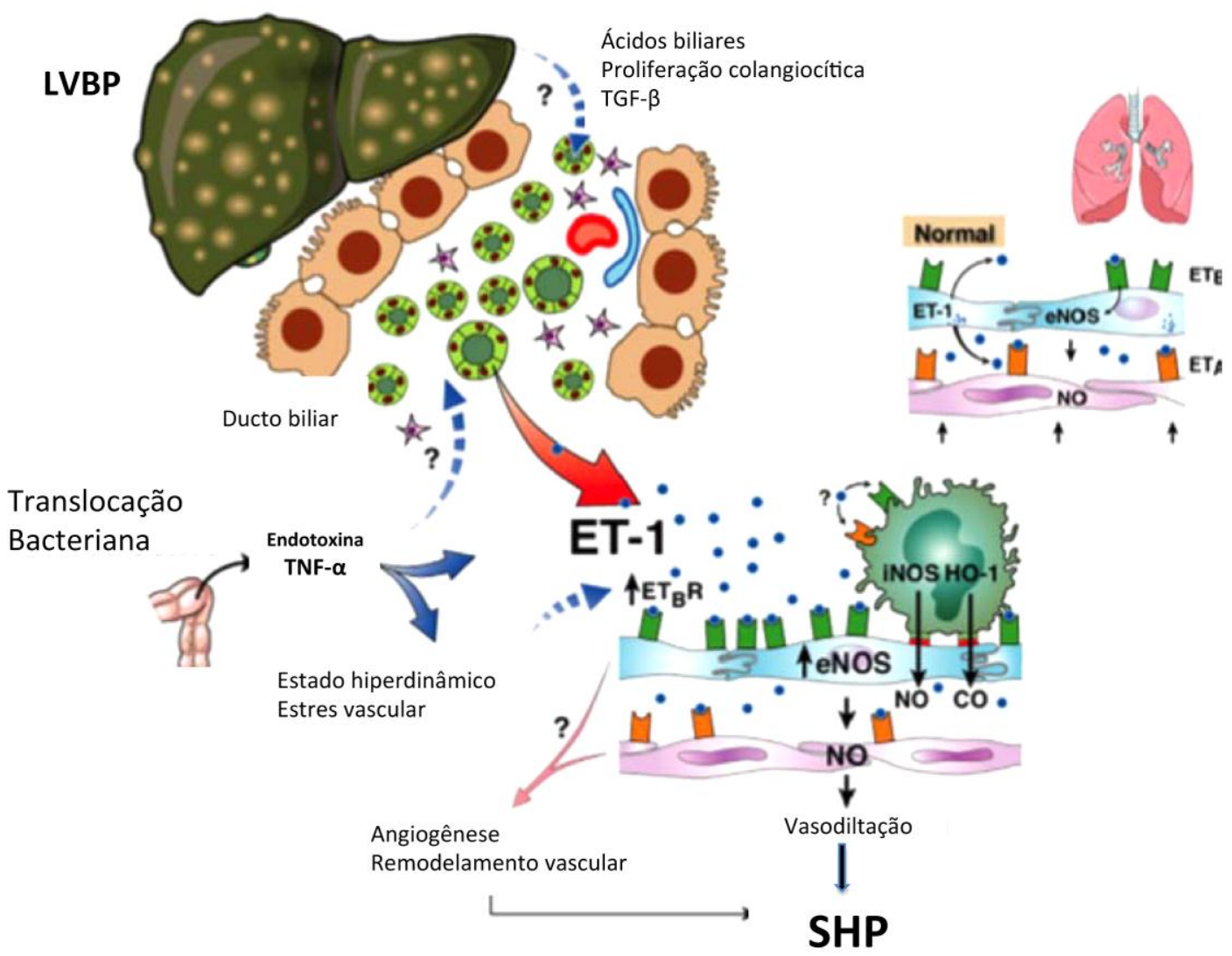

Figura 1 - Fisiopatologia da SHP descrita a partir do modelo experimental

Palma DT, Fallon MB. The hepatopulmonary syndrome. Journal of Hepatology 2006. (1) (SHP - Síndrome hepatopulmonar; LVBP - ligadura da via biliar principal; ET-1 - endotelina 1; ET A - endotelina A; ET B - endotelina B; ET BR - receptor da endotelina B; eNOS - óxido nítrico sintase endotelial; $\mathrm{NO}$ - óxido nítrico; $\mathrm{CO}$ - monóxido de carbono; TNF- $\alpha$ - fator de necrose tumoral alfa; TGF- $\beta$ - fator de transformação do crescimento beta)

A fisiopatologia da hipoxemia na SHP é multifatorial sendo que os mecanismos predominantes incluem shunts intrapulmonares, comprometimento da relação ventilação-perfusão, baixa difusão, desequilíbrio da difusão-perfusão ou do gradiente de oxigenação alvéolo-capilar. ${ }^{(1,2,4,8,12)} \mathrm{O}$ diagnóstico baseia-se em métodos de imagem que identifiquem essas dilatações, como a ecocardiografia 
transtorácica com contraste ou a cintilografia de perfusão com $99 \mathrm{mT}$ c, além da análise de gases arteriais, para identificar elevação da diferença alvéolo-arterial de O2 ou hipoxemia. A importância do diagnóstico da SHP está em priorizar os candidatos ao transplante de fígado, uma vez que sua presença esta associada à pior prognóstico da doença hepática. ${ }^{(1-3)}$

A hipoxemia em pacientes com SHP responde inicialmente à suplementação de oxigênio através de cateter nasal sob baixo fluxo, porém posteriormente há necessidade maior de suplementação, até mesmo sob cânula de traqueostomia. Até o momento não há nenhuma intervenção farmacológica que melhore a oxigenação arterial e altere a história natural da SHP. Existem algumas substâncias utilizadas, mas com poucos relatos bem sucedidos como simpaticomiméticos, bismesilato de almitrina, bloqueadores estrogênicos, plasmaferese, indometacina, octreotide, azul de metileno, aspirina e inibidor N-nitro-L-arginine methyl ester (L-NAME). Já foram realizadas tentativas terapêuticas como shunt portossistêmico intra-hepático transjugular (TIPS) ou embolização arterial nas más formações arteriovenosas pulmonares como alternativas temporárias. No entanto o transplante de fígado é a única opção terapêutica eficaz, com resolução da SHP. ${ }^{(1-4,14)}$

Um dos modelos experimentais que reproduz a SHP pode ser obtido através da indução de cirrose biliar secundária pela ligadura do ducto biliar em ratos. Neste modelo de cirrose biliar secundária a SHP ocorre em torno de vinte e oito dias após a ligadura e secção da via biliar principal. ${ }^{(11,14,16-22)}$ Este modelo simula a doença devido às alterações decorrentes da reação inflamatória causada pela estase biliar, e a desorganização da arquitetura natural do parênquima, com áreas inflamatórias e da deposição de colágeno e fibrose. ${ }^{(9-11)}$ 
Com a demonstração prévia por alguns autores como Fallon et al., Kountouras et al. e Chang et al., a indução da cirrose biliar pela ligadura do colédoco em ratos é um modelo experimental já padronizado para a SHP. Estudos experimentais em ratos mostraram melhora da SHP com a administração de algumas substâncias como a pentoxifilina, n-acetilcisteína, azul de metileno, quercetina; e a análise da patogênese pulmonar e da gravidade na SHP. ${ }^{(8-13,15-21,23-27)}$

Estudo clínico avaliou a patogênese pulmonar em pacientes cirróticos com SHP através da significância clinica da expressão da atividade da mieloperoxidase (MPO) pulmonar e expressão iONS sendo observada um aumento na sua atividade na síndrome e esse achado podendo estar envolvida na produção do ON. ${ }^{(28)}$

O surfactante pulmonar é um complexo de lipoproteínas de superfície (fosfolipoproteínas - 90\%) e proteínas específicas (10\%) que são quatro: a proteína A do surfactante (SP-A principal), SP- B, SP - C e SP-D, sintetizadas e secretadas por células alveolares epiteliais tipo II. Apresenta como função o aumento da complacência pulmonar, reduzindo a tensão superficial, evitando a atelectasia e o colapso pulmonar. A ausência ou diminuição do surfactante está relacionada com a síndrome do desconforto respiratório, doença da membrana hialina e proteinose alveolar pulmonar, que são doenças que levam à disfunção respiratória importante. ${ }^{(29-34)}$

O pulmão é o local de produção da proteína A do surfactante (SP-A) e proteína D do surfactante (SP-D). Estas proteínas constituem uma importante defesa imune no pulmão normal. Elas desempenham papel importante na resposta à infecção, alergia e inflamação pulmonar. As proteínas SP-A e SP-D aumentam a resposta imune com fagocitose de organismos invasores, como bactérias e vírus. 
O papel da SP-A e SP-D na inflamação pulmonar auxilia em dois aspectos: gerar uma resposta inflamatória leve que pode ser crucial na prevenção de infecções graves; ou prevenir a inflamação crônica que pode vir a danificar o pulmão. ${ }^{(30,32)}$

A suplementação da SP-A em modelo em vivo demonstrou melhora na defesa imunológica, e também na função biofísica do surfactante. ${ }^{(30)}$ Estudos experimentais sugerem que a administração exógena do surfactante pulmonar apresenta efeito terapêutico sistêmico efetivo no tratamento da alergia, inflamação e infecção. ${ }^{(33,34)}$

$\mathrm{Na}$ investigação da expressão e da função da SP-A no pulmão de ratos com lesão pulmonar aguda induzida por pancreatite aguda observaram-se alterações patológicas marcantes no pâncreas e pulmão dos ratos. A expressão da proteína SP-A no pulmão dos ratos com pancreatite foi significantemente reduzida, mostrando uma correlação inversa com a extensão da lesão pulmonar. ${ }^{(23)} \mathrm{O}$ surfactante (SP-A) já foi utilizado como terapia de administração exógena nas doenças pulmonares da infância, sendo comprovados seus benefícios na proteção imune e antiinflamatória. ${ }^{(30)}$

Sendo células alveolares epiteliais do tipo II o principal local de produção pulmonar do surfactante, é de se esperar que haja alteração em seus níveis em processos inflamatórios pulmonares agudos ou crônicos. A SHP apresenta em sua fisiopatologia alterações com menor perfusão alveolar, alterações microvasculares e inflamação. Além do mais, a proteína A do surfactante mostrou-se consumida no pulmão em processos inflamatórios, contudo não existem relatos na literatura de sua avaliação na cirrose ou na SHP. 
2 Objetivo 
Avaliar a concentração da proteína A do surfactante na síndrome hepatopulmonar induzida em ratos. 
Os experimentos foram realizados no laboratório de investigação médica (LIM 37) da Disciplina de Transplantes de Órgãos do Aparelho Digestivo da Universidade de São Paulo (USP) e a avaliação da concentração da proteína A do surfactante no Instituto Butantan.

\subsection{Animais}

Ratos Wistar machos (200-250 g, LIM 37 / USP, São Paulo, Brasil) foram utilizados em todos os experimentos e foram alojados à $19 \pm 3^{\circ} \mathrm{C}$, com 12-h (06:00 h-18: 00 horas) em ciclo de luz artificial, com dois ou três animais por gaiola do mesmo grupo. Os animais tinham livre acesso à água da torneira e comida padrão durante todo o experimento. A ingestão de alimentos não foi medida. O estudo foi realizado de acordo com as diretrizes vigentes locais e nacionais para o bem-estar animal. Todos os animais receberam cuidado humanitário de acordo com os critérios descritos no "Guia para o Cuidado e Uso de Animais de Laboratório", elaborado pela Academia Nacional de Ciências e publicado pelo National Institutes of Health (NIH publicação 86-23 revisado em 1985). 


\subsection{Desenho do estudo/ modelo experimental}

Os animais foram submetidos a uma ligadura de ducto biliar principal (grupo de ligadura do colédoco - LVBP / $\mathrm{n}=16$ ) como descrito anteriormente por outros autores. ${ }^{(16,17)}$ Foi realizado laparotomia mediana, identificação e individualização do ducto biliar principal, procedendo sua dupla ligadura com algodão 3.0 e posterior secção de aproximadamente $0,5 \mathrm{~mm}$ de via biliar principal. No grupo Sham $(\mathrm{n}=8)$ os animais foram submetidos à laparotomia e identificação apenas do colédoco, sem ligadura. E o grupo controle $(n=5)$ foi submetido apenas à coleta dos exames e análises. Todos os procedimentos começaram com a anestesia intraperitoneal com cloridrato de cetamina $5 \%$ (Ketalar ${ }^{\circledR}$, Cristália), $30 \mathrm{mg} / \mathrm{kg}$, sendo realizada doses de manutenção quando necessário. Os animais foram mantidos aquecidos com lâmpada halógena de $45 \mathrm{~W}$ e $127 \mathrm{~V}$. A temperatura corporal foi monitorizada por um termómetro digital retal (YSI 4000A Precision Termómetro, EUA) e foi mantida entre $35^{\circ}$ e $37^{\circ} \mathrm{C}$. 


\section{FLUXOGRAMA DO EXPERIMENTO}

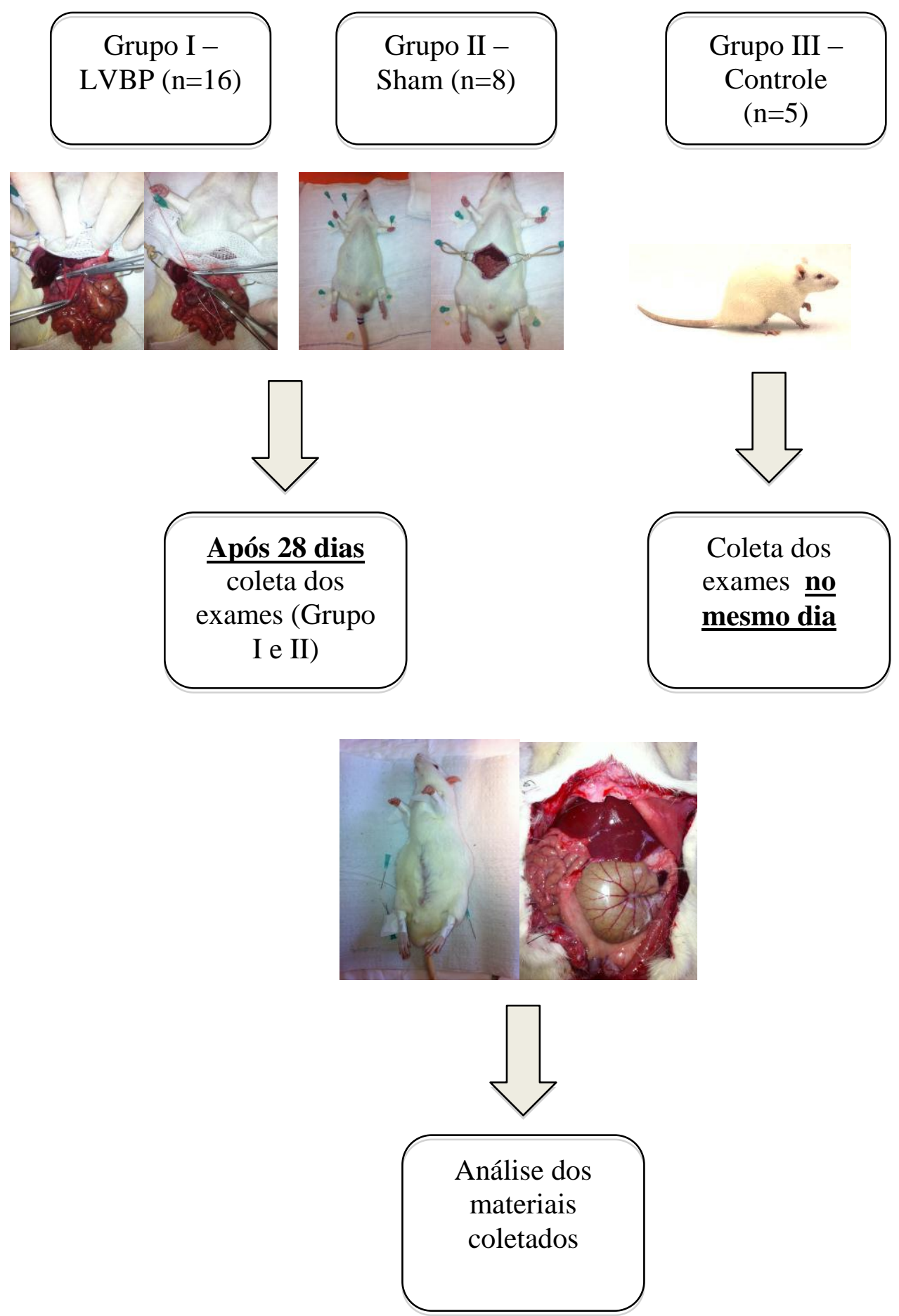

Figura 2 - Fluxograma do experimento 


\subsection{Análise de sangue arterial e venoso}

Depois de vinte e oito dias ${ }^{(16,17)}$, os animais foram anestesiados e submetidos à laparotomia. Amostras de sangue foram coletadas por punção da aorta abdominal e do coração. Depois disso, os animais foram sacrificados.

A gasometria arterial foi realizada em um radiômetro ABL 520 (Radiometer América, Westlake, $\mathrm{OH})$. As avaliações laboratoriais bioquímicas foram as seguintes: aspartato aminotransferase (AST), alanino aminotransferase (ALT), bilirrubina total (BT) e bilirrubina direta (BD), gama glutamil transferase (GGT) e fosfatase alcalina (FA). A quantificação da AST, ALT, BT, GGT e FA foi realizada pelo método otimizado ultravioleta (Cobas Mira, Roche) de acordo com a Federação Internacional de Química Clínica. Os resultados foram expressos em unidades por litro (U / L).

\subsection{Critérios de inclusão e exclusão}

Para a avaliação da proteína A do surfactante foram utilizados os seguintes critérios de inclusão: aumento na GGT > 30 U / L, BT > 5,0 U / L e BD > 4,0 U / L como indicadores de lesão hepática e alteração na gasometria arterial com PO2 $<80$ mmHg e diminuição de saturação de $\mathrm{O} 2<90 \%$ (Sat O2). ${ }^{(9,10,16,17)}$ Os critérios de exclusão foram o não estabelecimento dos dados acima, ou perda do animal por outra causa. 


\subsection{Avaliação da proteína A do surfactante (SP-A)}

A presença de SP-A nas amostras do homogenato pulmonar e soro dos ratos do grupo controle, grupo cirurgia simulada (Sham) e ratos com SHP (LVBP) foi avaliada utilizando um ensaio imunoenzimático ELISA indireto. Para a padronização do ensaio foram construídas curvas de calibração para certificar a qualidade e determinar as concentrações ótimas dos reagentes. Poços foram revestidos com as amostras diluídas em tampão de revestimento (carbonato-bicarbonato pH 9,6) durante a noite a $4^{\circ} \mathrm{C}$, seguido por bloqueio com soro fetal bovino a $10 \%$ em PBS-T. Após o bloqueio, o anticorpo policlonal foi adicionado antes da adição do segundo anticorpo (anticorpo de cabra anti IgG de coelho conjugado de peroxidase-Sigma). ${ }^{(31,35,36)}$ A concentração de SP-A foi expresso em ug / ml (Gráfico 1 e Tabela 1).

\subsubsection{Curva de calibração do soro policlonal de coelho anti-SP-A suína (pSP-A ab) (Gráfico 1)}

A curva de calibração foi construída relacionando o anticorpo com a proteína (SP-A) em diferentes concentrações e diluições (Gráfico 1). Foi possível detectar $1,25 \mu \mathrm{g} / \mathrm{ml}$ de SP-A para densidades ópticas acima de 0,5 , utilizando diluições do soro até 1:8000. A diluição 1:1600 do anticorpo foi escolhida e fixada para o ELISA das amostras provenientes de rato a fim de garantir densidades ópticas confiáveis (acima de 0,5) frente a estas amostras diluídas e testadas nas diluições 1:5, 1:10 e $1: 20$. 
Foi feita a diluição seriada da SP-A suína purificada com concentração inicial de $20 \mu \mathrm{g} / \mathrm{ml}$ e do anti-SPA suína com concentração inicial de 1:250. Os resultados obtidos podem ser vistos no gráfico abaixo:

Gráfico 1 - Relação entre SP-A suína e Densidade óptica

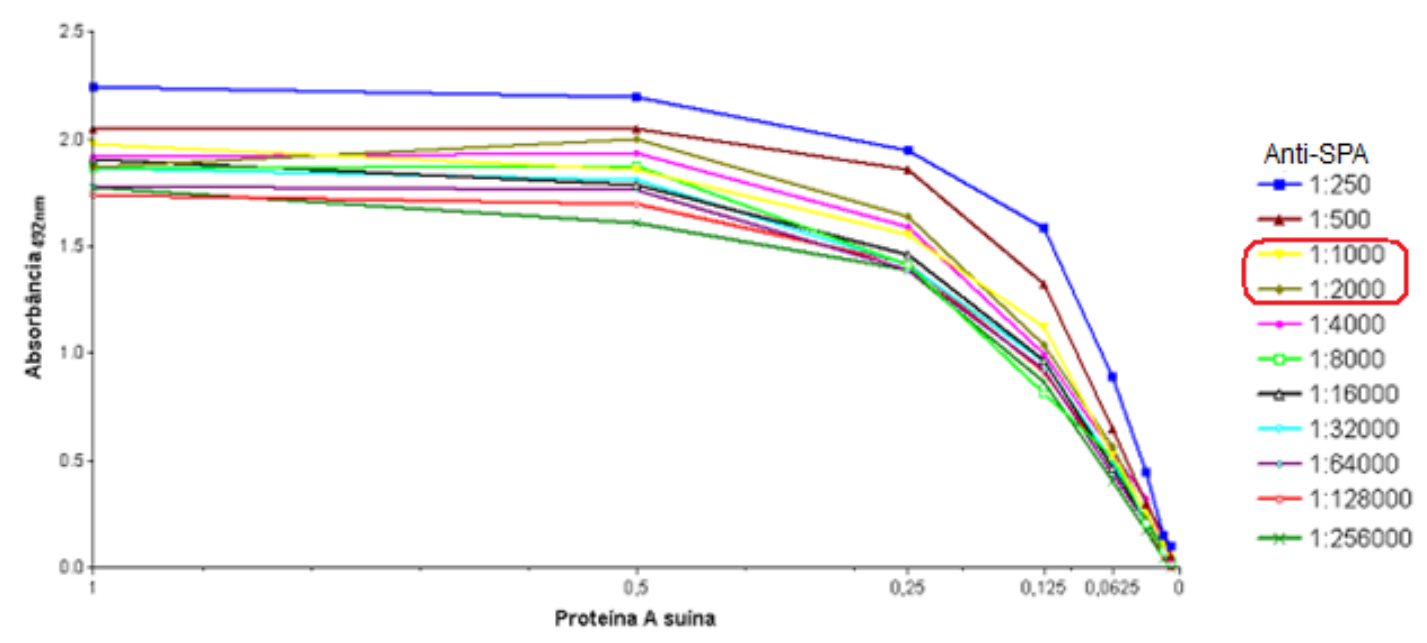

A partir do gráfico foi determinada que a concentração ideal do anti-SP-A é entre 1:1000 e 1:2000, padronizando uma concentração de 1:1600 para anti-SP-A.

Após a padronização da concentração do anti-SP-A (1:1600), foi determinada a concentração das amostras, onde foi escolhido a proporção de 1:5 das amostras em 1:1600 de anti-SP-A.

Tabela 1 - Padronização da concentração das amostras. Diluição do soro e homogenato, e a quantidade da proteína SP-A presente

\begin{tabular}{|c|c|c|c|c|c|c|c|}
\hline \multicolumn{2}{|c|}{ Proteína A suína } & & \multicolumn{2}{|c|}{ Coelho - anti-proteína A suína } & & & \\
\hline$\mu \mathrm{g} / \mathrm{ml}$ & $\mu \mathrm{g} / 50 \mu \mathrm{l}$ & & $\begin{array}{c}\text { Curva Padrão } \\
(1: 1600)\end{array}$ & $\begin{array}{c}\text { Amostra } \\
1: 1600\end{array}$ & & $\begin{array}{c}\mu \mathrm{g} / \mathrm{ml} \text { de SPA } \\
\text { total }\end{array}$ & \\
\hline 20 & 1 & $\mathrm{~A}$ & 2,546 & 0,652 & 1 & 6,2 & \multirow{4}{*}{ Soro } \\
\hline 10 & 0,5 & $\mathrm{~B}$ & 2,454 & 0,593 & $1: 5$ & 28,15 & \\
\hline 5 & 0,25 & C & 2,460 & 0,279 & $1: 10$ & 26,5 & \\
\hline 2,5 & 0,125 & $\mathrm{D}$ & 2,379 & 0,251 & $1: 20$ & 47,6 & \\
\hline 1,25 & 0,0625 & $\mathrm{E}$ & 1,604 & 1,042 & 1 & 8,3 & \multirow{4}{*}{ Homogenato } \\
\hline 0,625 & 0,031 & $\mathrm{~F}$ & 0,779 & 0,788 & $1: 5$ & 31,6 & \\
\hline 0,313 & 0,015 & $\mathrm{G}$ & 0,316 & 0,702 & $1: 10$ & 55,8 & \\
\hline 0,156 & 0,008 & $\mathrm{H}$ & 0,112 & 0,504 & $1: 20$ & 80,2 & \\
\hline
\end{tabular}




\subsection{Atividade da mieloperoxidase}

A atividade da mieloperoxidase (MPO) pulmonar foi utilizada como um indicador de neutrófilos sequestrados no pulmão. (28) As amostras foram homogeneizadas com Polytron usando PBS (phosphate buffered saline) contendo 0,5\% de EDTA (ácido etilenodiaminotretacético) hexadecilo e $5 \mathrm{mM}, \mathrm{pH}$ 6,0 foram sonicadas e, em seguida centrifugadas a 3000xg, 30 min. A atividade de MPO no sobrenadante foi determinada por densidade óptica (DO) a $460 \mathrm{~nm}$, devido a decomposição de $\mathrm{H} 2 \mathrm{O} 2$ na presença de O-dianisidina (Sigma). Os resultados foram expressos como densidade óptica a $460 \mathrm{~nm}$.

\subsection{Sacrifício e descarte}

Os animais foram sacrificados após 28 dias do início do experimento, sendo novamente pesados e anestesiados com cloridrato de cetamina; realizando-se a coleta dos materiais, sangue arterial e venoso, pulmão e fígado. Após a coleta os animais foram sacrificados com secção da aorta e da cava. Com a conclusão desses procedimentos, o animal previamente sacrificado foi embalado em saco plástico branco para descarte de material biológico, congelado e incinerado em local apropriado. 


\subsection{Método estatístico}

A análise estatística foi realizada utilizando GraphPad Prism Software®. Um valor de $\mathrm{p}<0.05$ foi considerado significativo. Os dados foram apresentados como média \pm desvio padrão (DP) para variáveis contínuas. O teste não paramétrico utilizado foi o teste de Kruskal-Wallis para determinar as diferenças significativas entre os três grupos e testes múltiplos de Dunn para realizar comparações múltiplas. 
4 Resultados 
Em nossos experimentos foram utilizados 35 ratos. Para o estabelecimento da SHP foram utilizados 20 ratos, que foram submetidos à ligadura do colédoco (3 excluídos por não estabelecimento de SHP e um morreu durante a anestesia). Para o grupo Sham foram utilizados 10 ratos (um morreu durante a anestesia e outro no segundo pós-operatório). O grupo controle foi composto por cinco ratos.

As alterações macroscópicas no grupo da cirurgia (LVBP) foram observadas após 28 dias da cirurgia, com a evidência do aumento do tamanho do fígado, com aspecto de colestase, contornos lobulados e bordas rombas em todos os ratos operados, além de esplenomegalia e escurecimento do parênquima pulmonar, com áreas de necrose presentes no tecido do pulmão (Figura 3A), quando comparados ao grupo Sham (Figura 3B) e também ao controle que apresentaram os órgãos com aspecto normal. 

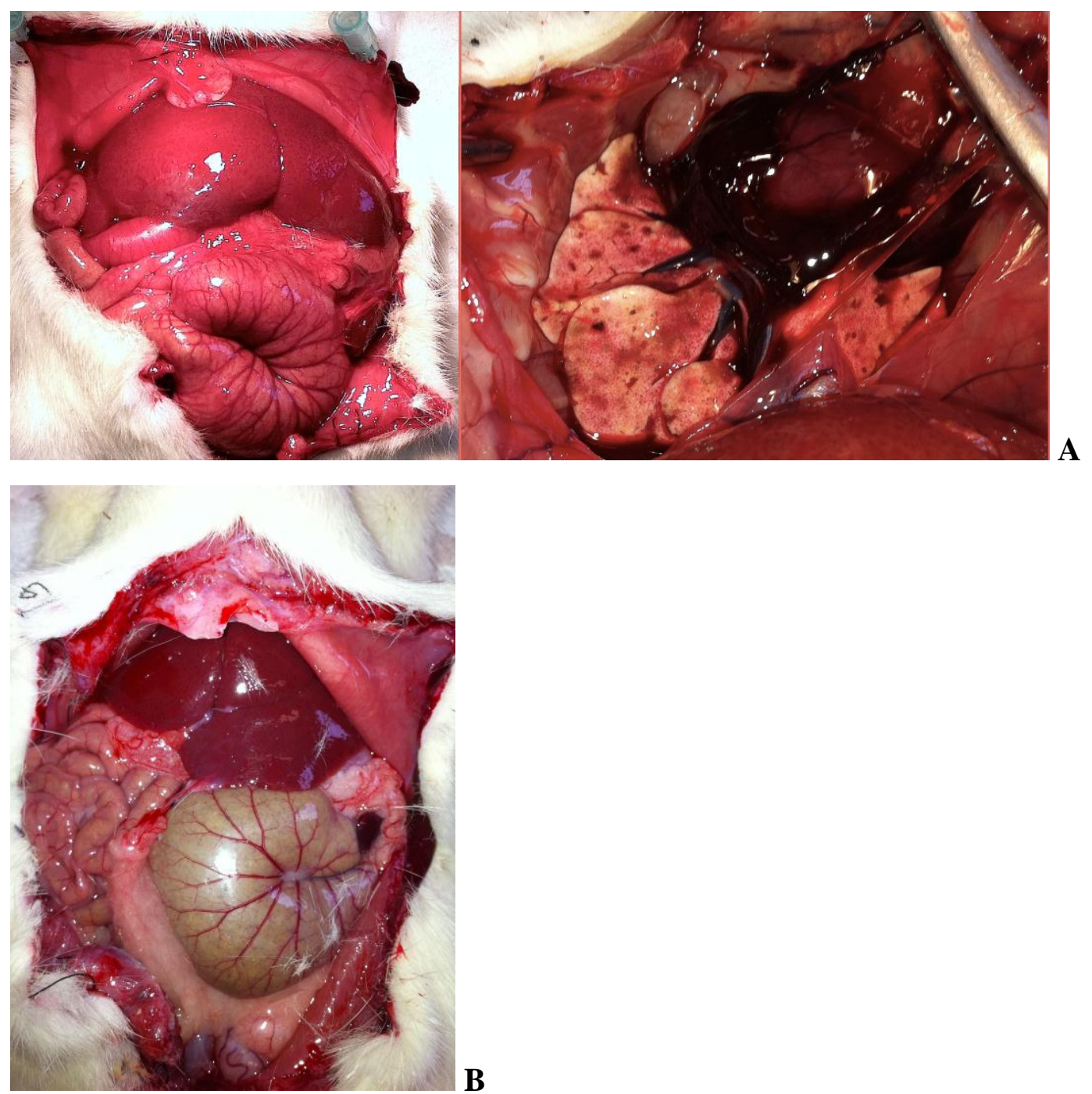

Figura 3 - Aspecto macroscópico do fígado e pulmão no grupo Ligadura da via biliar principal (A) e grupo Sham (B). Aspecto macroscópico do pulmão e fígado comparando os dois grupos mostrando a diferença macroscópica entre eles, com hepatopatia e lesão pulmonar no grupo operado. 
Os exames laboratoriais demonstraram o estabelecimento de hepatopatia no grupo com ligadura do colédoco com elevação das enzimas hepáticas (AST, ALT), aumento da bilirrubina total e direta (BT e BD), assim como GGT. Todos esses dados apresentados com significância estatística (Tabela 2 e Gráficos 2, 3, 4, 5). Somente a fosfatase alcalina (FA) não apresentou diferença estatística entre os grupos (Tabela 2 e Gráfico 6).

Tabela 2 - Resultado dos valores da bioquímica laboratorial, análise da gasometria arterial e da atividade da mieloperoxidase pulmonar

\section{Grupo Controle $(n=5) \quad$ Grupo Sham $(n=8) \quad$ Grupo LVBP $(n=16) \quad$ valor $p^{*}$}

\section{Parâmetros}

\begin{tabular}{lccccccc} 
AST(U/L) & 181.6 & $( \pm 52.88)$ & 114.8 & $( \pm 46.35)$ & 439.2 & $( \pm 177.3)$ & $<0.0001$ \\
ALT(U/L) & 59.80 & $( \pm 09.88)$ & 43.88 & $( \pm 15.08)$ & 592.1 & $( \pm 406.1)$ & $<0.0001$ \\
BT (U/L) & 00.10 & $( \pm 00.00)$ & 0.33 & $( \pm 0.15)$ & 06.32 & $( \pm 1.20)$ & $<0.0001$ \\
BD (U/L) & 00.00 & $( \pm 00,00)$ & 0.18 & $( \pm 0.08)$ & 04.65 & $( \pm 1.21)$ & $<0.0001$ \\
FA (U/L) & 368.2 & $( \pm 34.97)$ & 330.8 & $( \pm 211.7)$ & 592.1 & $( \pm 406.1)$ & 0.3780 \\
GGT (U/L) & 00.00 & $( \pm 00.00)$ & 4.62 & $( \pm 2.38)$ & 61.06 & $( \pm 29.72)$ & $<0.0001$ \\
PA O $(\mathrm{mmHg})$ & 79.74 & $( \pm 04.03)$ & 90.28 & $( \pm 9.11)$ & 72.74 & $( \pm 17.33)$ & 0.0014 \\
Sat $\mathrm{O}_{2}(\%)$ & 88.44 & $( \pm 01.37)$ & 97.33 & $( \pm 1.16)$ & 80.68 & $( \pm 16.96)$ & 0.0011 \\
MPO (U/mg) & 00.33 & $( \pm 00.01)$ & 00.02 & $( \pm 0.01)$ & 00.08 & $( \pm 00.03)$ & 0.002 \\
\hline
\end{tabular}

Nota: * valor do p, comparação entre o grupo controle vs grupo Sham vs grupo LVBP. Média e desvio padrão. LVBP; ligadura da via biliar principal; AST, aspartato aminotransferase; ALT, alanino aminotransferase; BT, bilirrubina total; BD, bilirrubina direta; GGT, gama glutamil transferase; FA, fosfatase alcalina; $\mathrm{PaO} 2$, pressão parcial de oxigênio; Sat O2, saturação de oxigênio; MPO, mieloperoxidase. 
Gráfico 2 - Avaliação da alanino aminotransferase (ALT) entre os grupos controle, Sham e ligadura da via biliar principal (LVBP). $(\mathrm{p}<0,0001 / / * \mathrm{p}<0,05 / * * * \mathrm{P}<0,001$; unidade U/L)

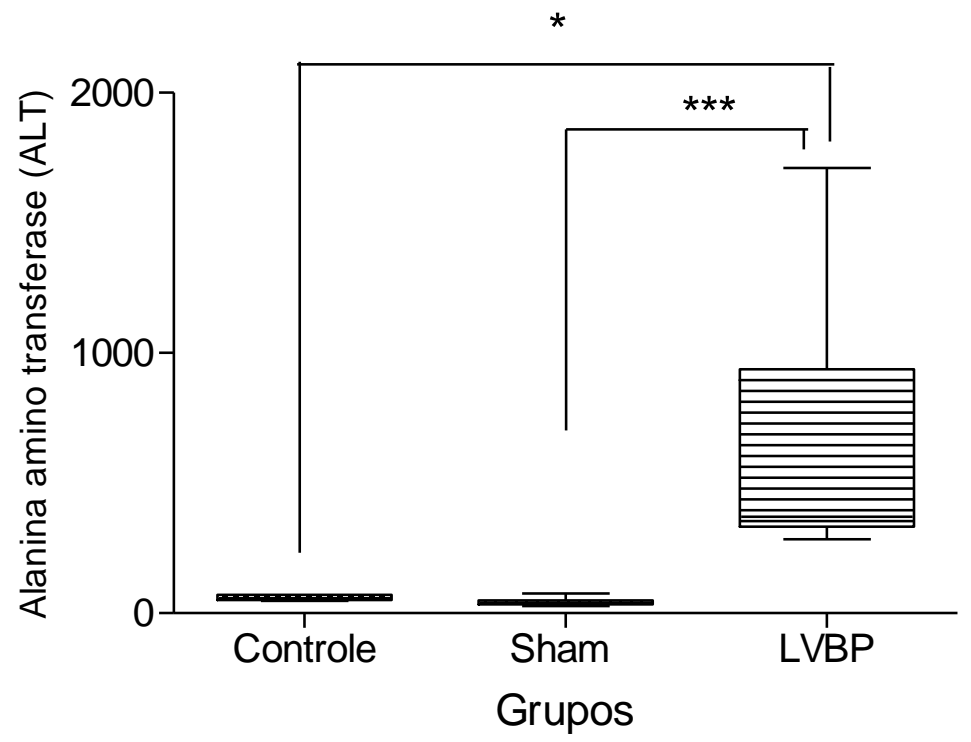

Gráfico 3 - Avaliação da aspartato aminotransferase (AST) entre os grupos controle, Sham e ligadura da via biliar principal (LVBP). ( $\mathrm{p}=0,0001 / / * * * \mathrm{p}<0,001$; unidade U/L)

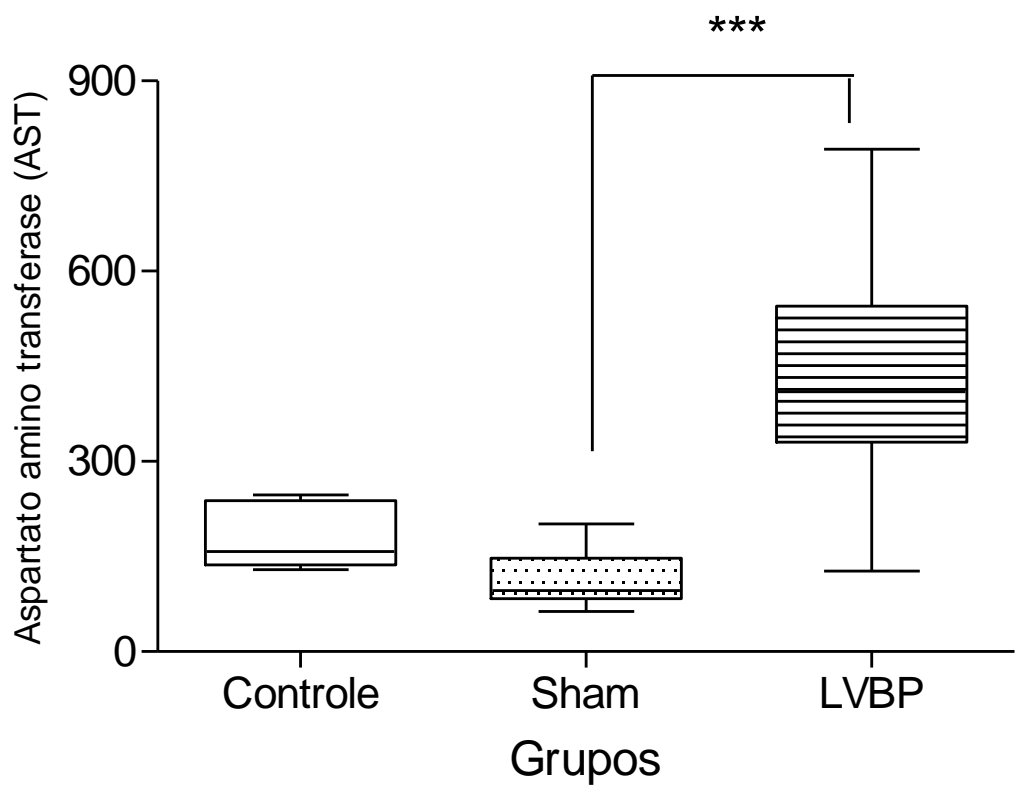


Gráfico 4 - Avaliação da Bilirrubina Total e Bilirrubina Direta nos grupos controle, Sham e ligadura da via biliar principal (LVBP)

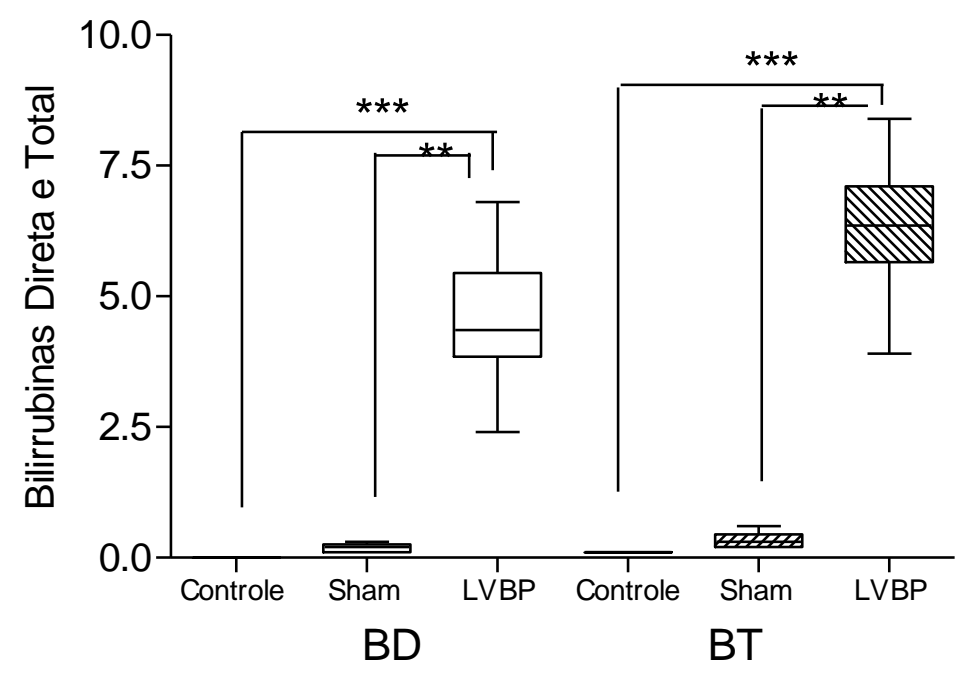

[(BD - $\mathrm{p}<0,0001 / / * * * \mathrm{p}<0,001 / * * \mathrm{p}<0,01)(\mathrm{BT}-\mathrm{p}<0,0001 / / * * * \mathrm{p}<0,001 / * *$ $\mathrm{p}<0,01)$; unidade U/L ]

Gráfico 5 - Avaliação da GGT (gama glutamil transferase) nos grupos controle, Sham e ligadura da via biliar principal (LVBP). (p<0,0001// *** $\mathrm{p}<0,001 / * *$ $\mathrm{p}<0,001$, unidade $\mathrm{U} / \mathrm{L})$

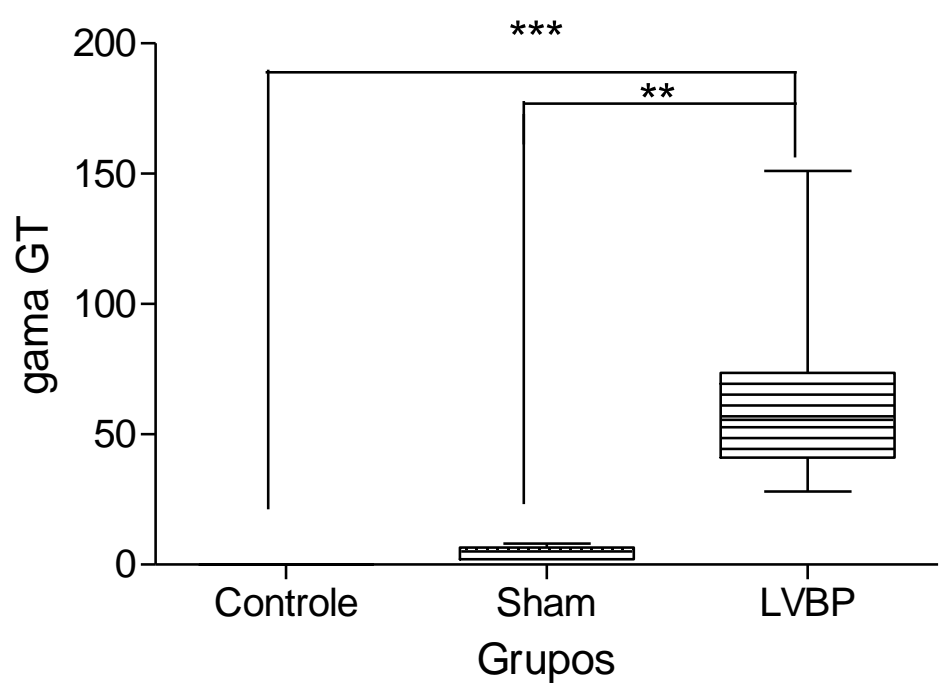


Os Grupos Controle e Sham apresentaram valores semelhantes em todos os exames laboratoriais realizados e menores que o grupo com ligadura da via biliar. Apenas o valor FA que não apresentou diferença estatística com o grupo de ligadura do colédoco.

Gráfico 6 - Avaliação da fosfatase alcalina nos três grupos controle, Sham e ligadura da via biliar principal (LVBP). ( $\mathrm{p} \mathrm{n} / \mathrm{s} / / \mathrm{p}=0,3780$; unidade U/L)

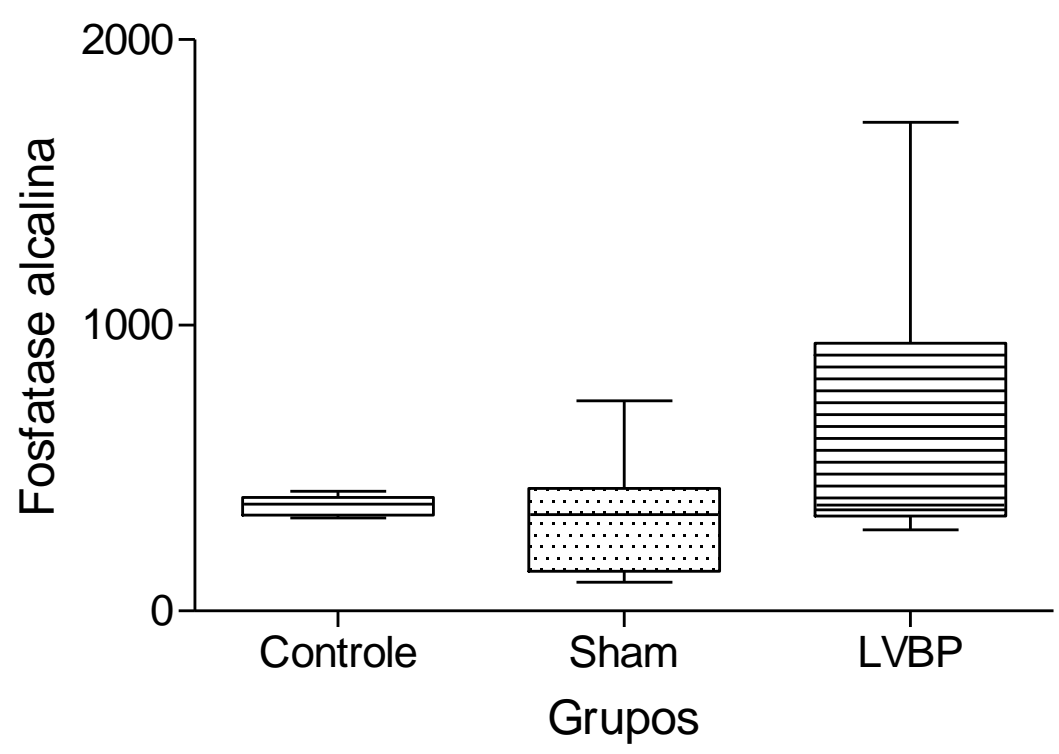


A avaliação do sangue arterial no grupo de ligadura do colédoco mostrou níveis mais baixos de PO2 e saturação de $\mathrm{O} 2(\mathrm{p}=0,0011$ e $\mathrm{p}=0,0014$, respectivamente) (Tabela 2 / Gráficos 7 e 8).

Gráfico 7 - Avaliação da $\mathrm{PaO} 2$ nos grupos controle, Sham e ligadura da via biliar principal (LVBP). $(\mathrm{p}=0,0014 / / * * \mathrm{p}<0,001)$

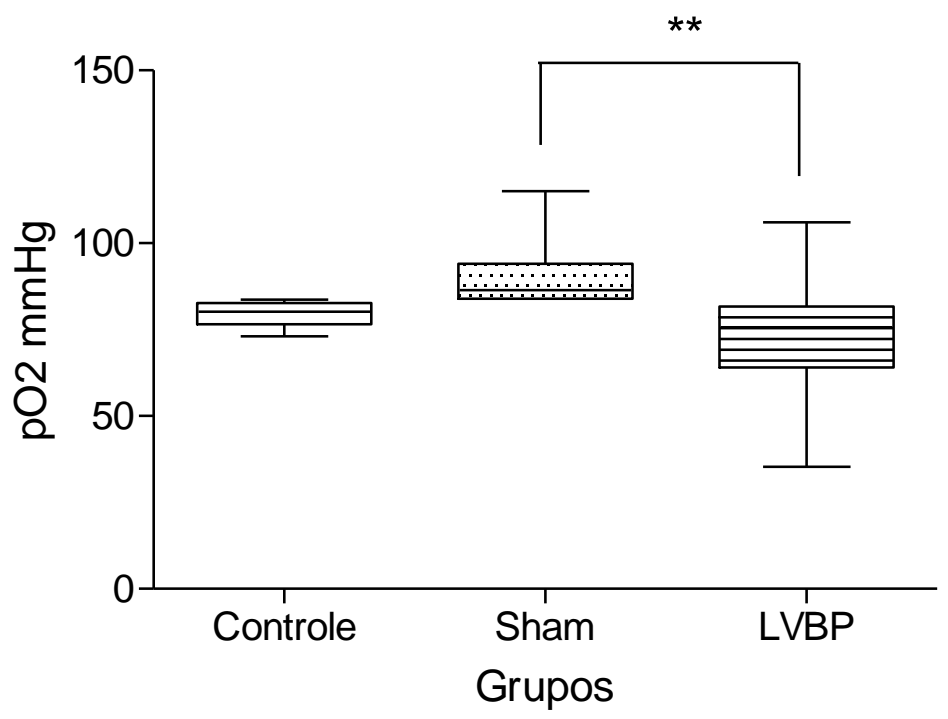

Gráfico 8 - Avaliação saturação de oxigênio nos grupos controle, Sham e ligadura da via biliar principal (LVBP). $(\mathrm{p}=0,0011 / / * \mathrm{p}<0,05 / * * \mathrm{p}<0,01)$

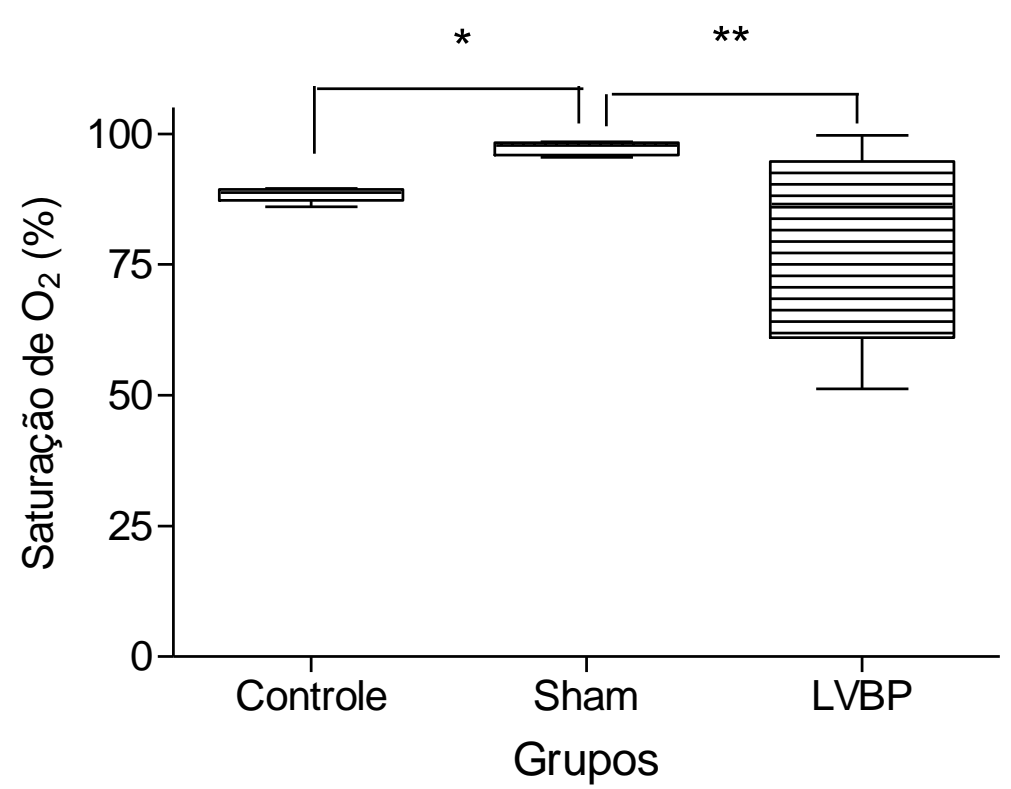


A atividade da MPO no grupo com ligadura do colédoco foi maior do que nos outros dois grupos $(\mathrm{p}=0,002)$. Não houve diferença estatística entre o grupo controle e o grupo Sham. (Tabela 2 / Gráfico 9)

Gráfico 9 - Avaliação da mieloperoxidase (MPO) nos grupos controle, Sham e ligadura da via biliar principal(LVBP). $(\mathrm{p}=0,0002 / / * * \mathrm{p}<0,01 / * * \mathrm{p}<0,01)$

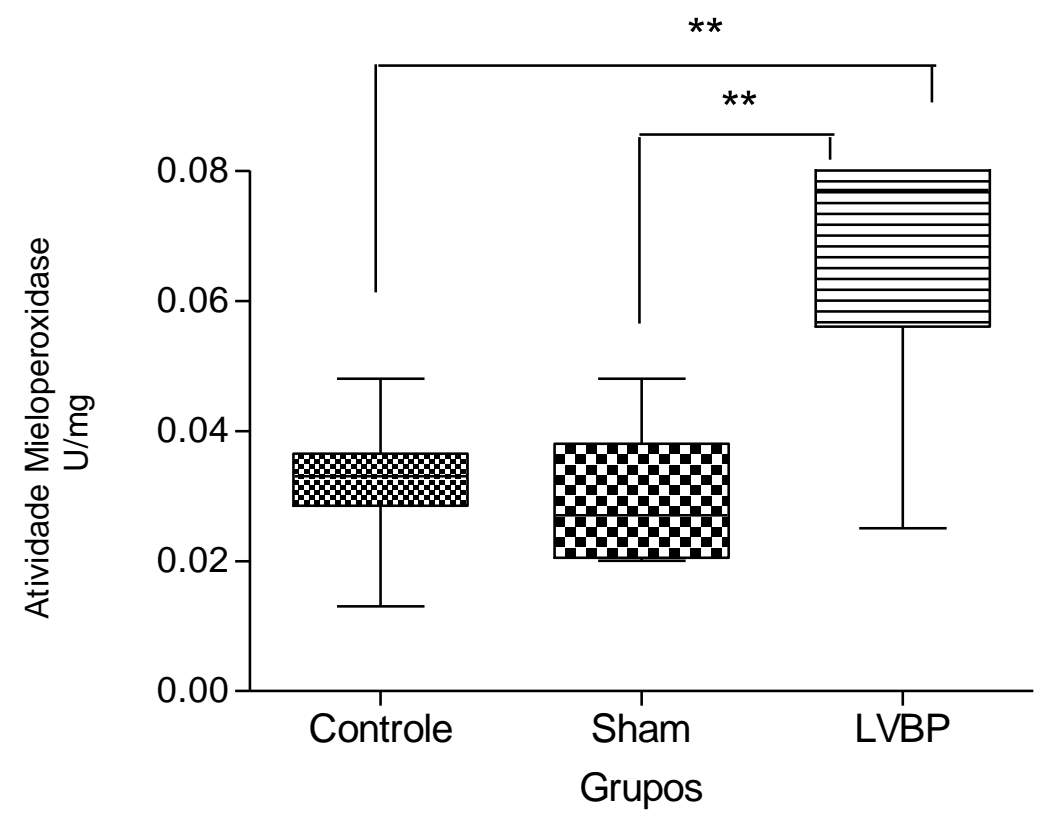


A avaliação da proteína A do surfactante (SP-A) no homogenato pulmonar apresentou valores menores no grupo Sham e ligadura do colédoco em comparação ao grupo controle $(\mathrm{p}<0,01)$, mostrando um consumo pulmonar de SP-A na SHP e no grupo com laparotomia (Sham). Esse consumo pulmonar refletiu em diminuição dos níveis séricos apenas no grupo Sham, com valores menores quando comparados ao grupo controle ( $\mathrm{p}<0,05)$. O grupo com SHP (ligadura do colédoco), no entanto apresentou valores séricos semelhantes ao do grupo controle. (Tabela 3 / Gráfico 10).

Tabela 3 - Avaliação da proteína A do surfactante sérica e no homogenato pulmonar

\begin{tabular}{|c|c|c|c|c|}
\hline & Grupo controle $(n=5)$ & Grupo Sham $(n=8)$ & Grupo LVBP $(n=16)$ & $\mathbf{p}^{*}$ \\
\hline \multicolumn{5}{|l|}{ Parâmetros } \\
\hline $\mathrm{SP}-\mathrm{A}$ sérica $(\mu \mathrm{g} / \mathrm{ml})$ & $0.88 \quad( \pm 0.23)$ & $0.39( \pm 0.14)$ & $0.84( \pm 0.23)$ & 0.0035 \\
\hline $\begin{array}{l}\text { SP-A homogenato } \\
\text { pulmonar }(\mu \mathrm{g} / \mathrm{ml})\end{array}$ & $3.00 \quad( \pm 0.53)$ & $1.55( \pm 0.12)$ & $1.85( \pm 0.61)$ & 0.0024 \\
\hline
\end{tabular}

Nota: *p valor, comparação entre o grupo controle vs grupo Sham vs grupo LVBP. Média e desvio padrão. LVBP; ligadura da via biliar principal; SP-A, proteína A do surfactante. 
Gráfico 10 - Avaliação da SP-A no homogenato pulmonar nos três grupos. $(\mathrm{p}=0,0024 / / * * \mathrm{p}<0,01 / * * \mathrm{p}<0,01) \quad(\mathrm{SP}-\mathrm{A}$ - proteína A do surfactante; LVBP- ligadura da via biliar principal)

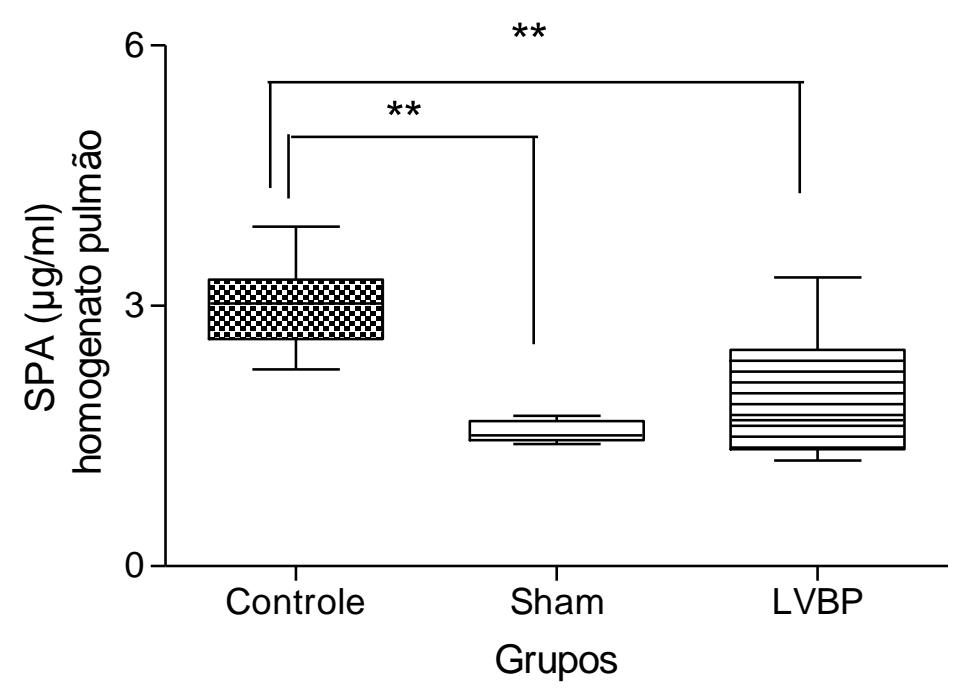

Gráfico 11 - Avaliação da SP-A sérica nos três grupos controle, Sham e ligadura da via biliar principal. $(\mathrm{p}=0,0035 / / * \mathrm{p}<0,05 / * * \mathrm{p}<0,01)(\mathrm{SP}-\mathrm{A}-$ proteína A do surfactante; LVBP- ligadura da via biliar principal)

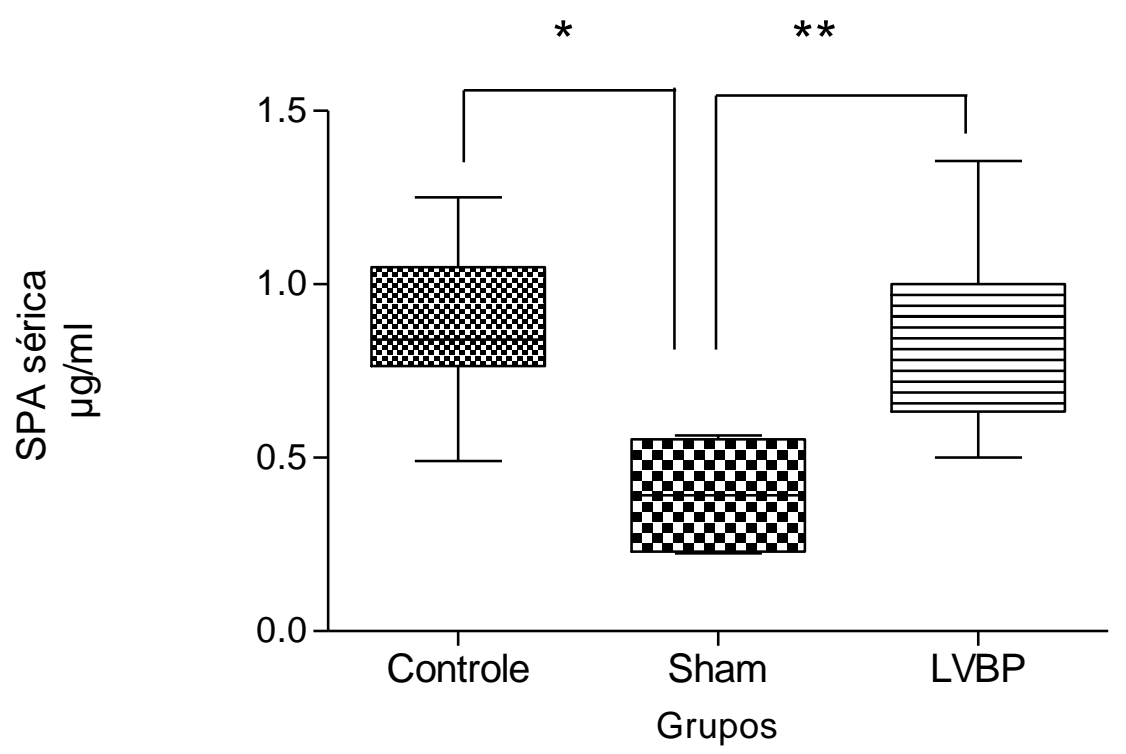


Em relação à avaliação histológica, não foi realizada a análise estatística entre os grupos. Apresentamos somente imagens ilustrativas que apresentam no grupo com ligadura da via biliar pneumopatia com aumento do edema alveolar e do volume de fibras elásticas no pulmão (Figura 4A). O achado histológico no fígado da representação deste grupo mostrou fibrose e células inflamatórias (Figura 4B).

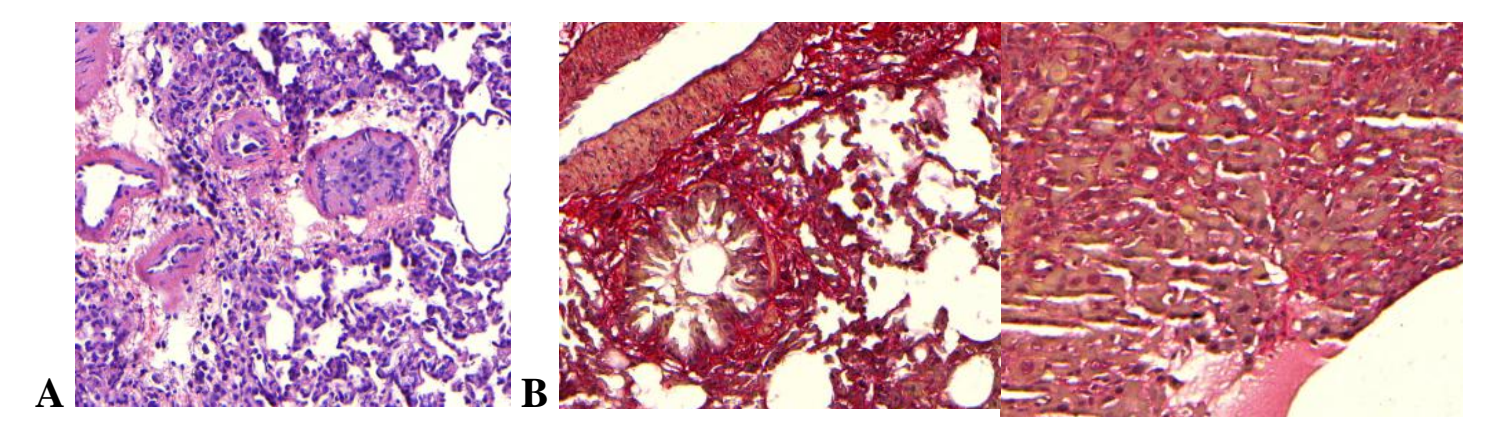

Nota: A - Tecido pulmonar corado com Verhoef; B - Tecido hepático corado com Picrosirius no aumento de 200x.

Figura 4 - Achados histológicos ilustrativos no Grupo Ligadura da via biliar principal (LBVP) demonstrando aspecto de síndrome hepatopulmonar. A: aumento do edema alveolar e do volume de fibras elásticas no pulmão do grupo operado; B: fibrose e células inflamatórias. 
Este é o primeiro estudo que avaliou o surfactante na SHP. Curiosamente, observou-se que não só na SHP, mas também num processo inflamatório sistêmico o surfactante do pulmão foi consumido. Além disso, foi também observado um desequilíbrio entre o nível de surfactante sérico e no homogenato pulmonar na SHP.

Como demonstrado por alguns autores a indução de cirrose por ligadura do ducto biliar comum (ligadura do colédoco) em ratos é um modelo experimental previamente descrito e conhecido para o estabelecimento da SHP. ${ }^{(16,17)}$ O estudo realizado está em conformidade com a literatura. Com este modelo descrito, este estudo obteve mais de $85 \%$ do desenvolvimento da SHP nos animais do experimento.

A Síndrome hepatopulmonar (SHP) após ligadura de ducto biliar principal em ratos resultam em mudanças moleculares pulmonares que podem ser influenciadas por TNF- $\alpha$ circulante e pelo aumento do estresse de cisalhamento vascular. Tal alteração na microvasculatura pulmonar ocasiona aumento do receptor da endotelina B (ETB) e óxido nítrico sintase endotelial (eNOS) que contribuem para a produção de óxido nítrico (ON) e para o desenvolvimento de SHP experimental. Alguns estudos experimentais em ratos mostraram uma melhora da SHP com a administração de certas substâncias que atuam de diferentes maneiras na fisiopatologia da síndrome, tais como: a pentoxifilina - melhorou significativamente a SHP sem alterar a hemodinâmica portal ou sistêmica, com a diminuição dos níveis do receptor ETB pulmonar e da expressão e ativação eNOS. Estas alterações foram associadas com 
uma redução nos níveis circulantes de TNF, apresentando efeitos direto na microvasculatura pulmonar ${ }^{(21)} ; \quad N$-acetilcisteína - melhora nos parâmetros enzimáticos e gasometria arterial, uma redução de lipoperoxidação e nos nitratos totais após o tratamento com $\mathrm{N}$-acetilcisteína. A análise histológica revelou vasodilatação no pulmão, que foi revertida por $\mathrm{N}$-acetilcisteína. A frequência de micronúcleos e danos ao DNA no pulmão e fígado foram aumentados no grupo com ligadura do colédoco. A N-acetilcisteína não causou nenhum efeito genotóxico e não influenciou na indução de micronúcleos na medula óssea e danos ao DNA no pulmão e fígado ${ }^{(12)}$; azul de metileno - O exame histológico dos pulmões indicaram que o tratamento com azul de metileno reduziu a proliferação de vasos capilares alveolares e a angiogênese, conduzindo à melhoria da oxigenação arterial ${ }^{(20)}$; a quercetina inibiu o stress oxidativo e a expressão de diferentes mediadores envolvidos na SHP. A quercetina também melhorou a lesão hepática e reduziu a expressão hepática de endotelina-1 em ratos cirróticos não tratados. ${ }^{(26)}$ Entretanto, nenhum deles encontrou uma drástica mudança no curso da doença.

Apesar de algumas substâncias mencionadas acima terem sido testadas experimentalmente na SHP, as proteínas do surfactante ainda não foram testadas nesta síndrome.

As proteínas do surfactante, como a SP-A e SP-D, são membros de uma família de moléculas do sistema imunológico inato, chamado colectinas. A função mais bem definida dos colectinas é a sua capacidade para opsonizar agentes patogênicos, incluindo bactérias e vírus, regulando uma variedade de funções celulares imunitárias; e facilitar a fagocitose por células imunes, tais como macrófagos e monócitos. ${ }^{(30,31,36)}$ Wu et al. mostraram que a SP-A e SP-D têm atividades 
bactericidas, além da atividade bem descrita de opsonização e capacidade de regular a produção de mediadores inflamatórios. ${ }^{(34)}$

Os estudos iniciais sobre surfactante pulmonar pretendiam compreender sua função mecânica e estrutural, como as partículas se interagiam com o meio de deposição inicial. Buscavam otimizar e contribuir com as propriedades de surfactante para serem utilizados na síndrome da angústia respiratória do recém-nascido e adulto. ${ }^{(29)}$

A presença de SP-A no soro do sangue foi relatada em fibrose pulmonar. ${ }^{(37)}$ O presente estudo verificou não só no grupo com inflamação pulmonar, mas em todos os grupos do experimento a presença de SP-A no sangue. Verificou-se que com o trauma cirúrgico (Sham) ocorreu um consumo de surfactante e consequente diminuição no soro. Por outro lado, na SHP, a SP-A pulmonar foi também consumida, mas observou-se um desequilíbrio entre os níveis séricos de surfactante e no homogenato pulmonar, ou seja, níveis baixos no pulmão e aumentados no sangue. O surfactante é produzido pelo pulmão, e a SHP começa com inflamação pulmonar que progressivamente evolui para shunts vasculares. Esta alteração inflamatória e vascular pode explicar por que na SHP a SP-A pulmonar é consumida enquanto a SP-A sérica continua com níveis mais elevados semelhantes aos do controle.

A explicação parece simples, mas uma questão que permanece é que o grupo de ligadura da via biliar também foi submetido à laparotomia e diferentemente a SP-A sérica não foi consumida. Já foi demonstrado que a SP-A aumenta na circulação de pacientes com síndrome da deficiência respiratória aguda e edema agudo de pulmão cardiogênico. ${ }^{(37)}$ Provavelmente aqui o surfactante foi muito produzido inicialmente devido à inflamação pulmonar e parte dele consumido pelo 
trauma cirúrgico. Mas, mais tarde, o aparecimento de shunts vasculares prejudicaria o equilíbrio entre os compartimentos do corpo e do surfactante no sangue permanecendo mais elevado nesta fase mais tardia. Certamente é necessário mais pesquisas para confirmar esta hipótese, mas podemos especular que os medicamentos administrados por via intravenosa na SHP podem não ter os mesmos níveis no pulmão do que em outras doenças.

Zhang et al. investigaram a expressão e função de SP-A no pulmão (homogenato) de ratos com lesão pulmonar aguda induzida por pancreatite aguda grave. Utilizaram vinte ratos Sprague-Dawley (SD) divididos aleatoriamente em dois grupos: grupo de operação simulada (placebo, $\mathrm{n}=10$ ) e grupo do modelo de pancreatite aguda grave (PAG) (PAG, $\mathrm{n}=10)$. A expressão da SP-A no pulmão foi detectada por reação em cadeia de polimerase e avaliada por imuno-histoquímica nos tecidos pulmonares. A expressão de SP-A no pulmão de ratos com pancreatite foi significativamente reduzida, mostrando uma correlação inversa com o grau da injúria no pulmão. Eles sugeriram que as células epiteliais alveolares tipo II podem desempenhar um papel importante na lesão pulmonar induzida por pancreatite aguda grave. ${ }^{(23)}$

Goto et al. investigaram o papel da SP-A em modelo murino de lesão aguda pulmonar não infecciosa induzida pelo tratamento com bleomicina. Com isso observaram que a SP-A desempenha papel importante na modulação da inflamação. A SP-A foi capaz de deprimir a indução da apoptose de células epiteliais in vitro, e a integridade epitelial no pulmão em resposta ao processo agudo não infeccioso. ${ }^{(38)}$

Os níveis de mieloperoxidase (MPO) e óxido nítrico sintase induzível (iNOS) já foram encontradas significativamente aumentadas no grupo de SHP em 
comparação com o grupo não-SHP. Esta expressão em pacientes cirróticos com síndrome hepatopulmonar (SHP) foi explorado por Wang et al. em 2010 e propõem que a MPO pode estar envolvida na regulação da iNOS. ${ }^{(28)}$

Em concordância com estudos anteriores nós também observamos uma maior atividade da MPO no grupo com ligadura do colédoco quando comparado com os outros dois grupos do trabalho. A maior atividade da MPO no grupo com ligadura do colédoco reforça o desenvolvimento de maior inflamação pulmonar na SHP, o que era esperado.

Em relação aos valores da pressão parcial de oxigênio (PAO2) e a saturação de oxigênio (Sat O2), observamos uma queda importante nos valores representando a hipoxemia nos ratos com síndrome hepatopulmonar quando comparamos com os ratos da cirurgia simulada. Este dado representa realmente o estabelecimento da síndrome hepatopulmonar nos ratos com ligadura da via biliar principal. Um fato que nos chamou a atenção foi em relação aos valores do grupo controle, que apresentaram níveis menores do que inicialmente esperávamos, estando menor que o grupo Sham. Tal acontecimento pode ter ocorrido pelo fato dos animais terem recebido uma dosagem de anestésico, apesar de adequada para o peso, no limite superior e evoluírem com hipóxia, devido também ao seu menor peso comparado com os outros dois grupos que estavam 28 dias mais velhos. De qualquer forma os valores foram maiores que no grupo com ligadura da via biliar.

Como já relatado o surfactante apresenta um importante papel na resposta inflamatória ${ }^{(30,34)}$ e parece haver um consumo ou diminuição de sua produção neste processo inflamatório. O presente trabalho confirma a diminuição do surfactante neste processo de inflamação pulmonar, e além disso, de maneira interessante ocorre 
um desbalanço entre os níveis séricos e pulmonares de SP-A quando a síndrome hepatopulmonar já esta instalada.

A idéia original para esta pesquisa foi de administrar o surfactante na SHP com o racional de sua propriedade anti-inflamatória, sua localização e produção pulmonar, seu efeito de melhora na complacência pulmonar, entre outros. No entanto, vimos que não há na literatura a dosagem dos níveis de surfactante, especificamente da proteína A do surfactante, na SHP e nem se quer nos animais de experimentação utilizados neste trabalho em condições normais. Foi optado então inicialmente, pela avaliação da proteína $\mathrm{A}$ do surfactante na síndrome hepatopulmonar e nos grupos Sham e controle neste modelo experimental. A sequência nesta linha de pesquisa será a avaliação da administração da proteína A do surfactante na SHP. 


\section{Conclusão}


A proteína A do surfactante encontra-se diminuída no homogenato pulmonar na síndrome hepatopulmonar em ratos.

Existe um desbalanço entre os níveis séricos e os níveis no homogenato pulmonar da proteína A do surfactante na síndrome hepatopulmonar em ratos. 


\section{Referências}


1. Palma DT, Fallon MB. The hepatopulmonary syndrome. $J$ Hepatol. 2006;45(4):617-25.

2. Lima B, Martinelli A, França AV. [Hepatopulmonary syndrome: pathogenesis, diagnosis and treatment]. Arq Gastroenterol. 2004;41(4):250-8.

3. Zhang J, Fallon MB. Hepatopulmonary syndrome: update on pathogenesis and clinical features. Nat Rev Gastroenterol Hepatol. 2012;9(9):539-49.

4. Fallon MB. Mechanisms of pulmonary vascular complications of liver disease: hepatopulmonary syndrome. J Clin Gastroenterol. 2005;39(4 Suppl 2):S138-42.

5. Machicao VI, Fallon MB. Hepatopulmonary syndrome. Semin Respir Crit Care Med. 2012;33(1):11-6.

6. Krowka MJ, Dickson ER, Wiesner RH, Krom RA, Atkinson B, Cortese DA. A prospective study of pulmonary function and gas exchange following liver transplantation. Chest. 1992;102(4):1161-6.

7. Rodríguez-Roisin R, Krowka MJ, Hervé P, Fallon MB, Committee ETFPHVDPS. Pulmonary-Hepatic vascular Disorders (PHD). Eur Respir J. 2004;24(5):861-80.

8. Luo B, Tang L, Wang Z, Zhang J, Ling Y, Feng W, et al. Cholangiocyte endothelin 1 and transforming growth factor betal production in rat experimental hepatopulmonary syndrome. Gastroenterology. 2005;129(2):68295.

9. Tieppo J, Vercelino R, Dias AS, Marroni CA, Marroni N. [Common bile duct ligation as a model of hepatopulmonary syndrome and oxidative stress]. Arq Gastroenterol. 2005;42(4):244-8. 
10. Vercelino R, Tieppo J, Forgiarini Junior LA, Dias AS, Marroni CA, Marroni NP. [Experimental models for assessment of pulmonary alterations in hepatopulmonary syndrome]. J Bras Pneumol. 2008;34(7):453-60.

11. Frossard JL, Schiffer E, Cikirikcioglu B, Bourquin J, Morel DR, Pastor CM. Opposite regulation of endothelial NO synthase by HSP90 and caveolin in liver and lungs of rats with hepatopulmonary syndrome. Am J Physiol Gastrointest Liver Physiol. 2007;293(4):G864-70.

12. Vercelino R, Tieppo J, Dias AS, Marroni CA, Garcia E, Meurer L, et al. Nacetylcysteine effects on genotoxic and oxidative stress parameters in cirrhotic rats with hepatopulmonary syndrome. Basic Clin Pharmacol Toxicol. 2008;102(4):370-6.

13. Zhang J, Ling Y, Tang L, Luo B, Pollock DM, Fallon MB. Attenuation of experimental hepatopulmonary syndrome in endothelin B receptor-deficient rats. Am J Physiol Gastrointest Liver Physiol. 2009;296(4):G704-8.

14. Zhang J, Luo B, Tang L, Wang Y, Stockard CR, Kadish I, et al. Pulmonary angiogenesis in a rat model of hepatopulmonary syndrome. Gastroenterology. 2009;136(3):1070-80.

15. Zhang J, Yang W, Luo B, Hu B, Maheshwari A, Fallon MB. The role of $\mathrm{CX}(3) \mathrm{CL} 1 / \mathrm{CX}(3) \mathrm{CR} 1$ in pulmonary angiogenesis and intravascular monocyte accumulation in rat experimental hepatopulmonary syndrome. $J$ Hepatol. 2012;57(4):752-8.

16. Kountouras J, Billing BH, Scheuer PJ. Prolonged bile duct obstruction: a new experimental model for cirrhosis in the rat. Br J Exp Pathol. 1984;65(3):305-11.

17. Fallon MB, Abrams GA, McGrath JW, Hou Z, Luo B. Common bile duct ligation in the rat: a model of intrapulmonary vasodilatation and hepatopulmonary syndrome. Am J Physiol. 1997;272(4 Pt 1):G779-84.

18. Chang SW, Ohara N. Pulmonary circulatory dysfunction in rats with biliary cirrhosis. An animal model of the hepatopulmonary syndrome. Am Rev Respir Dis. 1992;145(4 Pt 1):798-805.

19. Katsuta Y, Zhang XJ, Ohsuga M, Akimoto T, Komeichi H, Shimizu S, et al. Arterial hypoxemia and intrapulmonary vasodilatation in rat models of portal hypertension. J Gastroenterol. 2005;40(8):811-9. 
20. Miyamoto A, Katsuta Y, Zhang XJ, Li HL, Ohsuga M, Komeichi H, et al. Effect of chronic methylene blue administration on hypoxemia in rats with common bile duct ligation. Hepatol Res. 2010;40(6):622-32.

21. Zhang J, Ling Y, Tang L, Luo B, Chacko BK, Patel RP, et al. Pentoxifylline attenuation of experimental hepatopulmonary syndrome. J Appl Physiol. 2007;102(3):949-55.

22. Imamura M, Luo B, Limbird J, Vitello A, Oka M, Ivy DD, et al. Hypoxic pulmonary hypertension is prevented in rats with common bile duct ligation. J Appl Physiol. 2005;98(2):739-47.

23. Zhang XM, Chen HL, Wang ZH. [The expression and function of pulmonary surfactant protein $\mathrm{A}$ in severe acute pancreatitis in rats]. Zhongguo Wei Zhong Bing Ji Jiu Yi Хие. 2008;20(7):390-2.

24. Tang L, Luo B, Patel RP, Ling Y, Zhang J, Fallon MB. Modulation of pulmonary endothelial endothelin $\mathrm{B}$ receptor expression and signaling: implications for experimental hepatopulmonary syndrome. Am J Physiol Lung Cell Mol Physiol. 2007;292(6):L1467-72.

25. Sztrymf B, Libert JM, Mougeot C, Lebrec D, Mazmanian M, Humbert M, et al. Cirrhotic rats with bacterial translocation have higher incidence and severity of hepatopulmonary syndrome. J Gastroenterol Hepatol. 2005;20(10):1538-44.

26. Tieppo J, Cuevas MJ, Vercelino R, Tuñón MJ, Marroni NP, González-Gallego J. Quercetin administration ameliorates pulmonary complications of cirrhosis in rats. J Nutr. 2009;139(7):1339-46.

27. Luo B, Liu L, Tang L, Zhang J, Stockard CR, Grizzle WE, et al. Increased pulmonary vascular endothelin B receptor expression and responsiveness to endothelin-1 in cirrhotic and portal hypertensive rats: a potential mechanism in experimental hepatopulmonary syndrome. J Hepatol. 2003;38(5):556-63.

28. Wang Y, Wang W, Zhang Y, Zhao X, Yang D. Clinical significance of a myeloperoxidase gene polymorphism and inducible nitric oxide synthase expression in cirrhotic patients with hepatopulmonary syndrome. J Huazhong Univ Sci Technolog Med Sci. 2010;30(4):437-42.

29. Schürch S, Possmayer F, Cheng S, Cockshutt AM. Pulmonary SP-A enhances adsorption and appears to induce surface sorting of lipid extract surfactant. Am J Physiol. 1992;263(2 Pt 1):L210-8. 
30. Bailey TC, Maruscak AA, Petersen A, White S, Lewis JF, Veldhuizen RA. Physiological effects of oxidized exogenous surfactant in vivo: effects of high tidal volume and surfactant protein A. Am J Physiol Lung Cell Mol Physiol. 2006;291(4):L703-9.

31. Kubrusly FS, Iourtov D, Leme E, Raw I. Pulmonary surfactant protein A isolation as a by-product of porcine pulmonary surfactant production. Biotechnol Appl Biochem. 2004;40(Pt 2):173-9.

32. Floros J, Wang G, Mikerov AN. Genetic complexity of the human innate host defense molecules, surfactant protein A1 (SP-A1) and SP-A2--impact on function. Crit Rev Eukaryot Gene Expr. 2009;19(2):125-37.

33. Wright JR. The "wisdom" of lung surfactant: balancing host defense and surface tension-reducing functions. Am J Physiol Lung Cell Mol Physiol. 2006;291(5):L847-50.

34. Wu YZ, Medjane S, Chabot S, Kubrusly FS, Raw I, Chignard M, et al. Surfactant protein-A and phosphatidylglycerol suppress type IIA phospholipase A2 synthesis via nuclear factor-kappaB. Am J Respir Crit Care Med. 2003;168(6):692-9.

35. Dias S, dos Santos F, Sakauchi D, Iourtov D, Raw I, Kubrusly F. The Porcine Pulmonary Surfactant Protein A (pSP-A) Immunogenicity Evaluation in the Murine Model Pharmacology \& Pharmacy 2010;1:27-32.

36. Precioso AR, Sakae PP, Mascaretti RS, Kubrusly FS, Gebara VC, Iourtov D, et al. Analysis of the immunogenicity and stability of a porcine pulmonary surfactant preparation administered in rabbits. Clinics (Sao Paulo). 2006;61(2):153-60.

37. Mazur W, Toljamo T, Ohlmeier S, Vuopala K, Nieminen P, Kobayashi H, et al. Elevation of surfactant protein A in plasma and sputum in cigarette smokers. Eur Respir J. 2011;38(2):277-84.

38. Goto H, Ledford JG, Mukherjee S, Noble PW, Williams KL, Wright JR. The role of surfactant protein A in bleomycin-induced acute lung injury. Am J Respir Crit Care Med. 2010;181(12):1336-44. 
Apêndices 
Resultado Projeto de Pesquisa

PR 761 - Dr. Lucas

\begin{tabular}{|c|c|c|c|c|c|c|}
\hline Rato & AST & ALT & GT & FA & BD & BT \\
\hline & & & & & & \\
\hline L 2 & 93 & 34 & 8 & 321 & 0,3 & 0,6 \\
\hline L 3 & 369 & 182 & 42 & 918 & 6,1 & 7,5 \\
\hline L 4 & 420 & 115 & 32 & 1710 & 6,5 & 7,3 \\
\hline L 5 & 581 & 157 & 28 & 958 & 5,4 & 6,2 \\
\hline L 6 & 300 & 102 & 40 & 1025 & 5,5 & 6,4 \\
\hline L 7 & 217 & 69 & 81 & 966 & 6,8 & 8,1 \\
\hline L 8 & 74 & 76 & 7 & 736 & 0,2 & 0,3 \\
\hline L 9 & 93 & 45 & 5 & 353 & 0,2 & 0,3 \\
\hline L 10 & 63 & 45 & 5 & 465 & 0,2 & 0,4 \\
\hline L 11 & 150 & 52 & 6 & 393 & 0,3 & 0,5 \\
\hline L 12 & 201 & 36 & 2 & 101 & 0,1 & 0,2 \\
\hline L 13 & 100 & 28 & 2 & 151 & 0,1 & 0,2 \\
\hline L 14 & 144 & 35 & 2 & 126 & 0,1 & 0,2 \\
\hline L 15 & 792 & 105 & 53 & 284 & 2,4 & 3,9 \\
\hline L 16 & 395 & 33 & 63 & 371 & 3,9 & 5,5 \\
\hline L 17 & 673 & 84 & 84 & 340 & 3,7 & 5,0 \\
\hline L 18 & 307 & 13 & 53 & 299 & 4,3 & 5,8 \\
\hline L 19 & 699 & 74 & 36 & 337 & 4,0 & 6,3 \\
\hline L 20 & 353 & 45 & 66 & 328 & 4,8 & 6,9 \\
\hline L 21 & 127 & 716 & 43 & 415 & 5,4 & 8,4 \\
\hline L 23 & 446 & 59 & 79 & 314 & 4,1 & 6,9 \\
\hline L 24 & 440 & 45 & 58 & 345 & 3,3 & 4,8 \\
\hline L 25 & 508 & 70 & 151 & 369 & 4,4 & 6,4 \\
\hline L 26 & 400 & 77 & 68 & 495 & 3,8 & 5,8 \\
\hline L 27 & 518 & 106 & 20 & 329 & 5,6 & 7,6 \\
\hline L 29 & 562 & 169 & 33 & 490 & 0,6 & 0,8 \\
\hline L 30 & 817 & 238 & 62 & 448 & 5,0 & 6,8 \\
\hline L 31 & 1046 & 241 & 59 & 561 & 4,1 & 5,7 \\
\hline L 32 & 307 & 97 & 167 & 315 & 5,6 & 8,5 \\
\hline L 33 & 621 & 163 & 39 & 483 & 4,5 & 6,6 \\
\hline L 34 & 571 & 146 & 43 & 296 & 5,2 & 7,6 \\
\hline L 35 & 553 & 122 & 48 & 396 & 5,9 & 7,8 \\
\hline L 36 & 388 & 120 & 58 & 420 & 5,9 & 7,9 \\
\hline & & & & & & \\
\hline
\end{tabular}




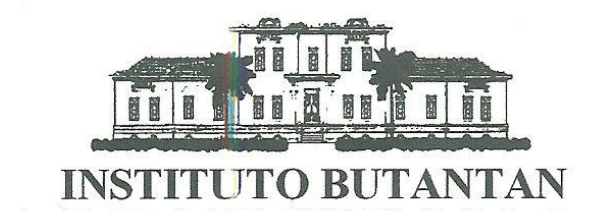

Av. Vital Brazil, 150005503900 São Paulo Brasil

Tel. $551137267222 \quad$ Fax. 551137261505

São Paulo 25 de agosto de 2010

Declaramos para fins de direito que 0 projeto "AVALIAÇÃO DA PROTEÍNA A DO SURFACTANTE NA SÍNDROME HEPATO-PULMONAR EM RATOS” do aluno Lucas Souto Nacif da FMUSP sob orientação dos profiessores Prof. Dr. Wellington Andraus e Prof. Dr. Luiz Augusto Carneiro D'Albuquerque (TRANSPLANTE DE ÓRGÃOS E APARELHO DIGESTIVO) será apoiado pelo nosso laboratório, uma vez que é também do nosso interesse testar exclusivamente para fins experimentais em modelo animal a proteína de origem suína que purificamos em nosso laboratório, objeto de uma de nossas linhas de pesquisa (DERIVADOS PROTÉICOSDE PULMÃO SUÍNO) sob nossa coordenação e sob a liderança científica do Prof.

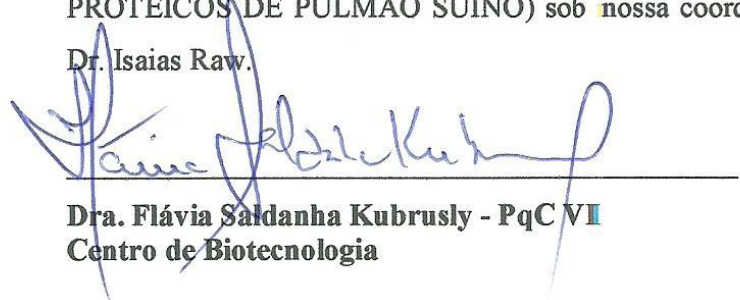

Ciente e de acordo:

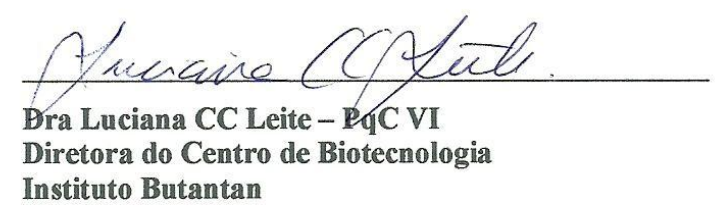



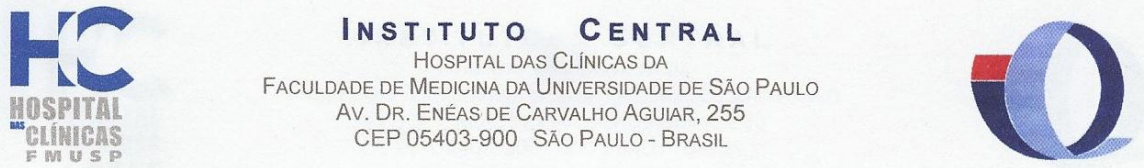

São Paulo, 21 de Março de 2011

ILMO(A). Sr(a).

Dr. Lucas Souto Nacif e Dr. Wellington Andraus

Disciplina de Transplante de Órgãos do Aparelho Digestivo da FMUSP

Referência: Projeto de Pesquisa: LACE

PR 761 "Avaliação da Proteína A do surfactante na síndrome hepato-pulmonar em ratos".

A Comissão de Ensino e Pesquisa da Divisão de Laboratório Central considerou exeqüível a realização da coleta de laboratório relacionados ao seu projeto de pesquisa. Informamos que V.s.a. poderá iniciá-lo conforme seu Cronograma, sendo que os pedidos de exames deverão ser preenchidos conforme modelo abaixo, a fim de evitarmos desvios nos resultados. É FUNDAMENTAL QUE V.S.a PROVIDENCIE UM CARIMBO PARA IDENTIFICAÇÃO DE SEU PROTOCOLO, conforme:

PR-761 CARIMBADO EM TODOS OS PEDIDOS DE EXAME, DE PREFERÊNCIA, COM TINTA VERMELHA.

No campo CLÍNICA: preencher com a palavra LACE

No campo PESQUISA PR 761

Com carimbo vermelho: PR 761

Qualquer dúvida ou necessidade de esclarecimentos, contactar Profa. Leila Antonangelo, relatora do projeto, pelo telefone 3069-6179.

$N^{\circ}$ total de pacientes no projeto: 40 ratos, sendo 01 análise por animal.
* TGO
* fosfatase alcalina
* TGP
* BTF
* GaMA GT
* GAsometrIA ARTERIAL

Análises serão realizadas no Laboratório de Animais;

O início do Projeto está vinculado à liberação do Laboratório de Animais, previsto para Abril/2011.

$\underline{C / C}$

LAB. DE ANIMAIS

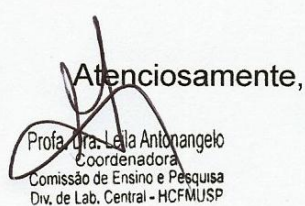




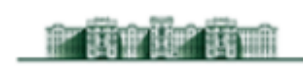 \\ MEDICINA \\ COMITÊ DE ÉTICA EM PESQUISA}

A CEUA do Comitê de Ética em Pesquisa da Faculdade de Medicina da Universidade de São Paulo, em sessão de 09.02.2011, APROVOU o Protocolo de Pesquisa $n^{\circ}$ o12/11 intitulado: "Avaliação da proteína A do surfactante na Síndrome Hepato-Pulmonar em ratos.", apresentado pelo Departamento de Gastroenterologia.

Cabe ao pesquisador elaborar e apresentar ao CEP-FMUSP, o relatório final sobre a pesquisa, ( Lei Procedimentos para o Uso Científico de Animais - Lei No 11.794-8 de outubro de 2008).

Pesquisador (a) Responsável: Wellington Andraus

Pesquisador (a) Executante: Lucas Souto Nacif

CEP-FMUSP, o9 de fevereiro de 2011.

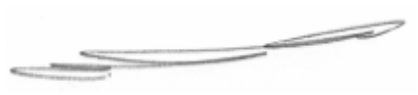

Dr. Eduardo Pompeu

Coordenador

Comissão de Ética no Uso de Animais

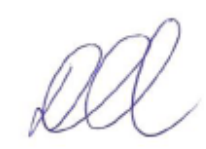

Prof. Dr. Daniel Romero Muñoz

Vice-coordenador

Comitê de Ética em Pesquisa

Comitê de Ética em Pesquisa da Faculdade de Medicina da Universidade de São Paulo

Av. Dr. Arnaldo , 455 - Instituto Oscar Freire $1^{\circ}$ andar CEP 01246903 - Fone : 3061-8004

mail: cep.fmusp@hcnet.usp.br 


\title{
The ILTS $18^{\text {th }}$ Annual International Congress
}

\author{
May 16-19, 2012 \\ Hilton San Francisco Union Square Hotel \\ San Francisco, CA \\ USA
}

\begin{abstract}
LB35
Evaluation of Surfactant Protein $A$ in Hepatopulmonary

Syndrome in Rats Lucas Souto Nacif ${ }^{1}$, Márcia Saldanha Kubrusly ${ }^{1}$, Flavia Saldanha Kubrusly ${ }^{2}$, Luiz Augusto Carneiro D'Albuquerque ${ }^{1}$, Andrea Ishizawa ${ }^{2}$, Vera C.B. Cainelli ${ }^{2}$, Wellington Andraus ${ }^{1}$. ${ }^{1}$ Gastroenterology, Sao Paulo University School of Medicine, São Paulo, Brazil; ' ${ }^{2}$ Centro de Biotecnologia, Instituto Butantan, São Paulo, Brazil

Introduction: Hepatopulmonary syndrome (HPS) is considered a clinical entity consisting of the triad: liver disease, intrapulmonary vascular dilatation (IPVD) and changes in blood gases. This condition is present in $4 \%$ to $32 \%$ of patients with cirrhosis. Its pathogenesis is not well defined, but it is speculated that the combination of factors such as the imbalance in the response of vascular endothelin receptors, pulmonary microvascular remodeling, genetic predisposition conducive to IPVD and bacterial translocation. One experimental model that reproduces HPS may be obtained through the induction of secondary biliary cirrhosis by bile duct ligation in rats. In this model of secondary biliary cirrhosis, HPS occurs in about twenty-eight days. The lung is the primary site of surfactant production (alveolar epithelial type II cells) and plays an important role in inflammatory lung injury and diseases of childhood, but there are no reports of changes in its expression in cirrhosis, much less in SHP. Methods: To determine and analyze these effects, three groups of rats were divided in control, sham and experimental HPS groups (eHPS).Results: We observed after 28 days of cirrhosis surgical inductionthe evidence of cirrhosis in all operated rats (eHPS) with a macroscopic cirrhotic liver, splenomegaly, ascites, elevated liver enzymes (AST , ALT), total and direct bilirubin (BT e BD) and canalicular enzymes ( GGT , FA) and arterial blood gas assessment of SHP (decreased PO2 and $\mathrm{O} 2$ saturation). We found histological changes characteristic of HPS in lung tissues and liver. The finding of the lung homogenate surfactant protein a (SP-A) were lower values in sham and eHPS group comparative with control group $(p<0.01)$. On the blood findings we observed SP-A on sham group with lower values when compared with control group $(\mathrm{p}<0,05)$ and eHPS group higher than sham group $(p<0,05)$. Conclusion: Our experimental model is in agreement with the literature to the establishment of HPS in rats. These initial findings of surfactant protein A (SP-A) suggest that this protein must play a role in the physiopathology of this syndrome (HPS).
\end{abstract}




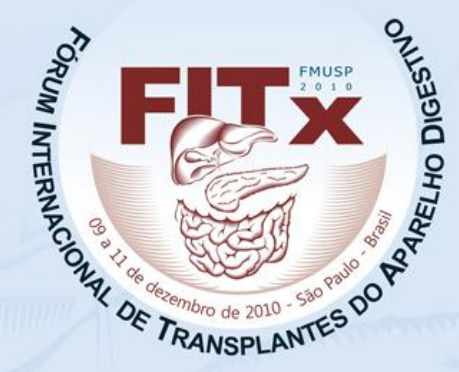

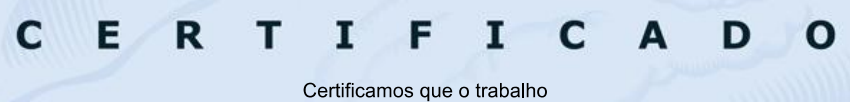

INDUÇÃO DE CIRROSE BILIAR SECUNDÁRIA E SÍNDROME HEPATOPULMONAR EM RATOS.

inscrito pelos autores LUCAS SOUTO NACIF, RENATA F. P. MENDES, RODRIGO POLIZIO, WELLINGTON ANDRAUS, LUIZ AUGUSTO CARNEIRO D'ALBUQUERQUE foi apresentado na Sessão de Poster do Fórum Internacional de Transplantes do Aparelho Digestivo realizado de 9 a 11 de dezembro de 2010 em São Paulo/SP/Brasil.

São Paulo, 11 de dezembro de 2010.<smiles>CCCCCC</smiles>

Prof

Prof. Dr. Luiz Carneiro D'Albuquerque

Professor Titular da Disciplina de Transplantede Órgăos do Aparelho Digestivo da FMUSP

Reneacio
A. LE.

MEDICIN

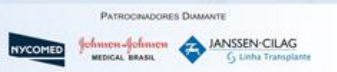

re dto (3) (2) 


\section{LUNG: Notification of Manuscript Number}

----- Forwarded message -----

From: "Lung (LUNG)" <naresh.santhanam @ springer.com>

Date: Fri, Jan 4, 2013 3:56 am

Subject: LUNG: Notification of Manuscript Number

To: "Wellington Andraus" <wellington@usp.br>

Dear Dr. Wellington Andraus,

We are in receipt of your manuscript titled "SURFACTANT PROTEIN A IS DECREASED IN THE LUNGS OF RATS WITH HEPATOPULMONARY SYNDROME" and thank you for having submitted it for eventual publication in Lung.

The manuscript has been registered under the number LUNG2255. Please use this reference in all future correspondence.

Submission of such a manuscript for publication implies that it has not been and will not be submitted to another journal during the editorial procedure.

Best regards,

Springer Journals Editorial Office

Lung 